ARTICLE

\title{
Interferon lambda 4 impairs hepatitis C viral antigen presentation and attenuates $\mathrm{T}$ cell responses
}

Qian Chen', Mairene Coto-Llerena (1) ', Aleksei Suslov', Raphael Dias Teixeira (1) 2, Isabel Fofana', Sandro Nuciforo (1) ${ }^{1}$, Maike Hofmann (1) ${ }^{3}$, Robert Thimme (1) ${ }^{3}$, Nina Hensel (1) ${ }^{3}$, Volker Lohmann (1) ${ }^{4}$, Charlotte K. Y. Ng (iD ${ }^{5}$, George Rosenberger ${ }^{1}$, Stefan Wieland (i) ${ }^{1}$ \& Markus H. Heim (i) ${ }^{1,6 凶}$

Genetic variants of the interferon lambda (IFNL) gene locus are strongly associated with spontaneous and IFN treatment-induced clearance of hepatitis C virus (HCV) infections. Individuals with the ancestral IFNL4-dG allele are not able to clear HCV in the acute phase and have more than a $90 \%$ probability to develop chronic hepatitis C (CHC). Paradoxically, the IFNL4-dG allele encodes a fully functional IFN $\lambda 4$ protein with antiviral activity against $\mathrm{HCV}$. Here we describe an effect of IFN $\lambda 4$ on $\mathrm{HCV}$ antigen presentation. Only minor amounts of IFN $\lambda 4$ are secreted, because the protein is largely retained in the endoplasmic reticulum (ER) where it induces ER stress. Stressed cells are significantly weaker activators of HCV specific CD8 ${ }^{+} \mathrm{T}$ cells than unstressed cells. This is not due to reduced $\mathrm{MHC}$ I surface presentation or extracellular IFN $\lambda 4$ effects, since $T$ cell responses are restored by exogenous loading of $\mathrm{MHC}$ with $\mathrm{HCV}$ antigens. Rather, IFN $\lambda 4$ induced ER stress impairs HCV antigen processing and/or loading onto the $\mathrm{MHC}$ I complex. Our results provide a potential explanation for the IFN $\lambda 4-H C V$ paradox.

\footnotetext{
${ }^{1}$ Department of Biomedicine, University of Basel, Basel, Switzerland. ${ }^{2}$ Biozentrum, University of Basel, Basel, Switzerland. ${ }^{3}$ Department of Medicine II, University Hospital Freiburg, Freiburg, Germany. ${ }^{4}$ Department of Infectious Diseases, Molecular Virology, Centre for Integrative Infectious Disease Research (CIID), University of Heidelberg, Heidelberg, Germany. ${ }^{5}$ Department for BioMedical Research (DBMR), Oncogenomics Lab, University of Bern, Bern, Switzerland. ${ }^{6}$ Clarunis, University Center for Gastrointestinal and Liver Diseases, Basel, Switzerland. $\varpi_{\text {email: markus.heim@unibas.ch }}$
} 
nterferon lambda (IFN $\lambda$ ) is generally recognized for its important role in innate immunity at mucosal barriers of the intestine and the respiratory $\operatorname{tract}^{1}$, but it is also an important regulator of the host response to Hepatitis $\mathrm{C}$ virus (HCV) infection. In 2009, genome-wide association studies unexpectedly linked genetic variants of the IFN-lambda (IFNL) gene locus with spontaneous and treatment-induced clearance of $\mathrm{HCV}^{2-7}$. Four years later, IFN $\lambda 4$ was discovered and identified as the molecular link between genotype and phenotype ${ }^{8}$. IFN $\lambda 4$ differs in several important ways from the other three IFN $\lambda$ family members. IFN $\lambda 4$ shares only $29 \%$ amino acid identity with its closest relative IFN $\lambda 3$, whereas the three other members of the family share $>80 \%{ }^{8}$. Compared with the other IFN $\lambda$ family members, IFN $\lambda 4$ is very weakly induced by viral infections, poorly expressed, and hardly secreted at all $^{9-14}$. These properties of IFN $\lambda 4$ make it difficult to explore functional properties that could explain its negative impact on defense against HCV. Years after its discovery, the most compelling evidence for the central role of IFN $\lambda 4$ still comes from genetic association studies. Genetic variations in the IFNL4 gene encode several isoforms. The IFNL4 signature single nucleotide polymorphism (SNP) at rs368234815 is an insertion/ substitution mutation (IFNL4-G/TT) that disrupts the open reading frame of the ancestral IFNL4-G allele in exon 1. A second functionally important SNP at rs117648444 (T/A) changes a proline at amino acid position 70 of the protein to serine, resulting in a much less active IFN $\lambda 4-S 70^{15}$. Paradoxically, the non-functional IFNL4-TT, the functionally impaired IFNL4-S70, and the fully functional IFNL4-P70 alleles are strongly associated with high, intermediate, and low spontaneous HCV clearance rates, respectively ${ }^{15}$. Why a functional IFN with strong in vitro antiviral activity ${ }^{10-12}$ can be a disadvantage in the host response to HCV remains unexplained.

In the present study, we use biochemical and immunological approaches to explore the biological properties of IFN $\lambda 4$. We confirm previous reports showing that IFN $\lambda 4$ is poorly secreted, but once secreted, binds to the IFN $\lambda$ receptor, strongly induces Jak-STAT signaling, and has strong antiviral activity. Here we describe that these positive effects on innate immunity are counteracted by a negative impact on cellular immunity. This negative effect comes from the non-secreted IFN $\lambda 4$ that accumulates in the endoplasmic reticulum (ER) and induces ER stress. ER stress leads to reduced antigen processing from endogenous $\mathrm{HCV}$ proteins, which in turn inhibits $\mathrm{HCV}$ antigen presentation to $\mathrm{CD}^{+} \mathrm{T}$ cells. As a consequence, $\mathrm{HCV}$-specific $\mathrm{T}$ cell responses are attenuated. Our findings provide mechanistic evidence that IFN $\lambda 4$ has a negative impact on antigen-dependent immune responses that could explain the "IFN $\lambda 4$ paradox".

\section{Results}

IFN $\lambda 4$ is poorly secreted but stimulates potent JAK-STAT signaling. The first description of IFN $\lambda 4$ in 2013 reported that transfection of cells with an IFN $\lambda 4$ expression plasmid induced the phosphorylation of the classical IFN signal transducers STAT1 and STAT2 despite the fact that IFN $\lambda 4$ protein could not be detected in the supernatant of the transfected cells ${ }^{8}$. In order to obtain further insights into IFN $\lambda 4$ production, glycosylation, and secretion, we transiently transfected Huh-7 cells with expression vectors encoding different Myc-tagged IFNs and monitored intracellular and extracellular accumulation. Forty-eight hours (h) post-transfection, total cell lysates and cell-culture supernatant were subjected to Myc-tag-specific (Fig. 1a, top panel) and IFNspecific (Fig. 1a, bottom panel) western blot analysis. As expected, IFN $\alpha$ and IFN $\lambda 1,2$, and 3 accumulated in the cell-culture supernatant (Fig. 1a). In contrast, IFN $\lambda 4$ accumulated intracellularly and was barely detectable in the supernatant (Fig. 1a).
The poor secretion of IFN $\lambda 4$ was not caused by the Myc-tag, because the same results were obtained using Flag-tagged versions of IFNa, IFN $\lambda 1-4$ (Supplementary Fig. 1). Next, we investigated the kinetics of IFN $\lambda 4$ secretion. To investigate the IFN production rate, we measured IFN $\lambda 3$ and IFN $\lambda 4$ production and intracellular accumulation in the cells during $120 \mathrm{~h}$ after transfection, and we quantified daily IFN secretion over a 5-day period (Fig. 1b-e). During the entire time of the experiment, IFN $\lambda 4$ was barely detectable in the supernatant but instead accumulated intracellularly, whereas IFN $\lambda 3$ was secreted as expected (Fig. 1b-e).

Next, we assessed the activity of the secreted IFN $\lambda 4$. To that end, we stimulated Huh-7 cells stably expressing the receptor IFN入R1 (Huh7-LR cells ${ }^{16}$ ) with serial dilutions of supernatant collected from cells transfected with IFN $\lambda 4$ or IFN $\lambda 3$ expression plasmids. IFN $\lambda 4$ samples strongly activated STAT1 and STAT2 phosphorylation (pY-STAT1, pY-STAT2) even in dilutions where the Myc-tagged protein was not detectable (Fig. 2a-c). This experiment was also performed in the presence of B18R, a type I IFN inhibitor ${ }^{17-19}$. Treatment of Huh7-LR cells with B18R prevented IFNa- but not IFN $\lambda 3$ - and IFN $\lambda 4$-mediated JAK-STAT activation (Fig. 2b, c and Supplementary Fig. 2). To further study the activity of IFN $\lambda 4$ in a time-dependent manner, we investigated the kinetics of STAT phosphorylation triggered by IFN $\lambda 4$ or IFN $\lambda 3$. Compared to IFN $\lambda 3$, IFN $\lambda 4$ activated STAT1 and STAT2 faster and stronger (Fig. 2d, e). For a more quantitative assessment of the specific activity of IFN $\lambda 3$ and IFN $\lambda 4$, we purified the proteins from cell-culture supernatants (Supplementary Fig. 3). Huh7-LR cells were then stimulated with different concentrations of the purified proteins (Supplementary Fig. 4a, b). Dose-response curves were generated and used to calculate EC50 values. The EC50 for STAT1 phosphorylation was 1.4 and $39.1 \mathrm{ng} / \mathrm{ml}$ for IFN $\lambda 4$ and IFN $\lambda 3$, respectively, and for STAT2 activation it was 1.9 and $54.3 \mathrm{ng} / \mathrm{ml}$ for IFN $\lambda 4$ and IFN $\lambda 3$, respectively. Thus, IFN $\lambda 4$ was approximately 28 -fold more potent than IFN $\lambda 3$. The high specific activity of IFN $\lambda 4$ was confirmed in Mx1-promoter-reporter gene assays (Supplementary Fig. 4c), by quantifying interferon-stimulated gene (ISG) expression (Supplementary Fig. 4d), and also demonstrated as antiviral activity in HCV replicon cells (Supplementary Fig. 4e). We conclude that IFN $\lambda 4$ is poorly secreted, but highly potent.

IFN $\lambda 4$ glycosylation increases its function. Next, we wanted to investigate what renders IFN $\lambda 4$ so potent. It has been described that posttranslational modification of IFN $\lambda 4$ by $\mathrm{N}$-linked glycosylation is required for secretion but apparently does not influence its activity ${ }^{10}$. Nevertheless, we explored whether glycosylation is also important for the activity of IFN $\lambda 4$. First, we compared pY-STAT1 activation in Huh7-LR cells that were treated with equal amounts of purified IFN $\lambda 4$ and IFN $\lambda 3$ produced in Huh7 cells (i.e., properly glycosylated) or Escherichia coli (E. coli) (i.e., lacking all glycosylation) as quantified by silver staining (Fig. 3a). In case of IFN $\lambda 3$, which is physiologically not glycosylated $^{20}$, there was no difference between E. coli and Huh7derived purified proteins in terms of STAT1 activation (Fig. 3b). This was different for IFN $\lambda 4$, where Huh7-derived preparations were much more potent (Fig. $3 \mathrm{~b}$ ), suggesting that glycosylation increased IFN $\lambda 4$ activity. To further investigate the role of glycosylation for IFN $\lambda 4$ activity, we pre-treated Huh-7-produced purified IFN $\lambda 4$ with different glycosidases prior to stimulation of Huh7-LR cells. Consistent with previous reports ${ }^{10}$, we observed in western blots a shift of IFN $\lambda 4$-specific bands to lower molecular weights in samples that were pre-treated with a mix of deglycosylation enzymes (PNGase F, O-glycosidase, neuraminidase, $\beta-1-4$ galactosidase, and $\beta-N$-acetyl glucosaminidase) or with PNGase F alone (Fig. 3c, lane 2 and 3 from the left), 
a

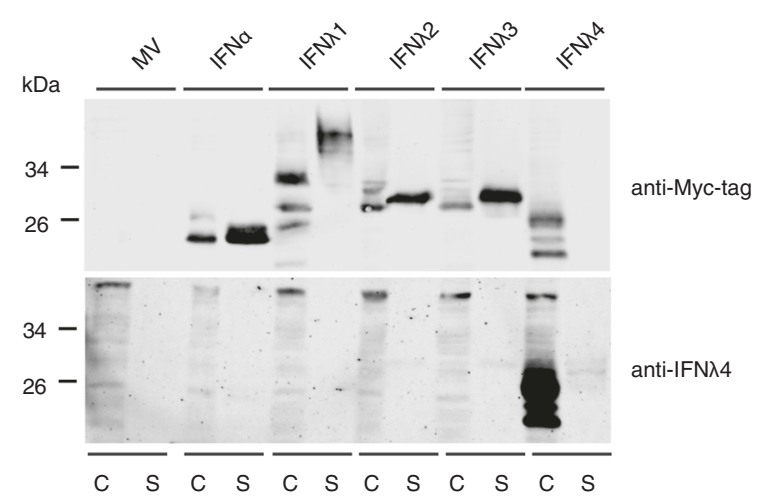

b

IFN $\lambda 4$

d

IFN $\lambda 3$

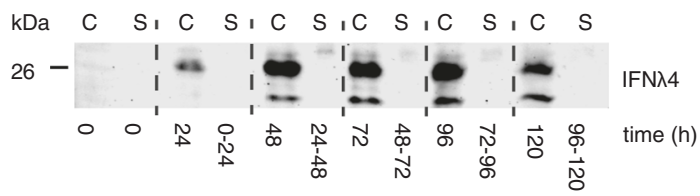

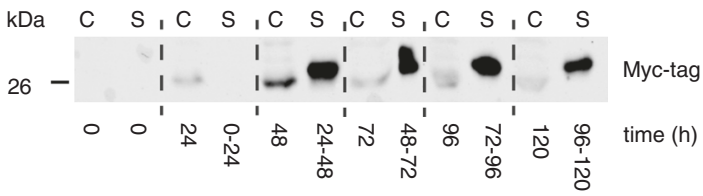

C

IFN $\lambda 4$

e

IFN $\lambda 3$
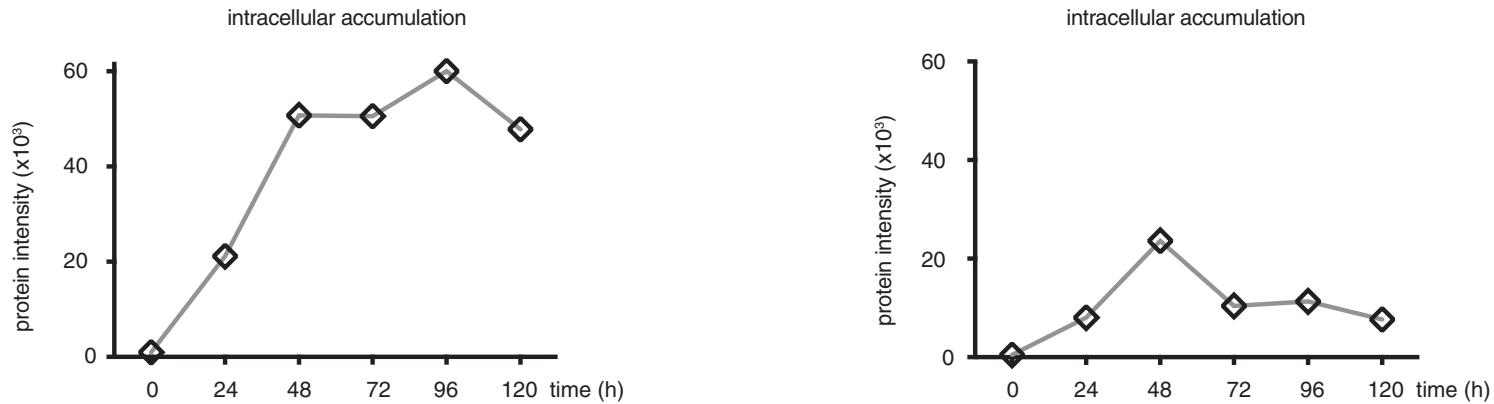

supernatant production
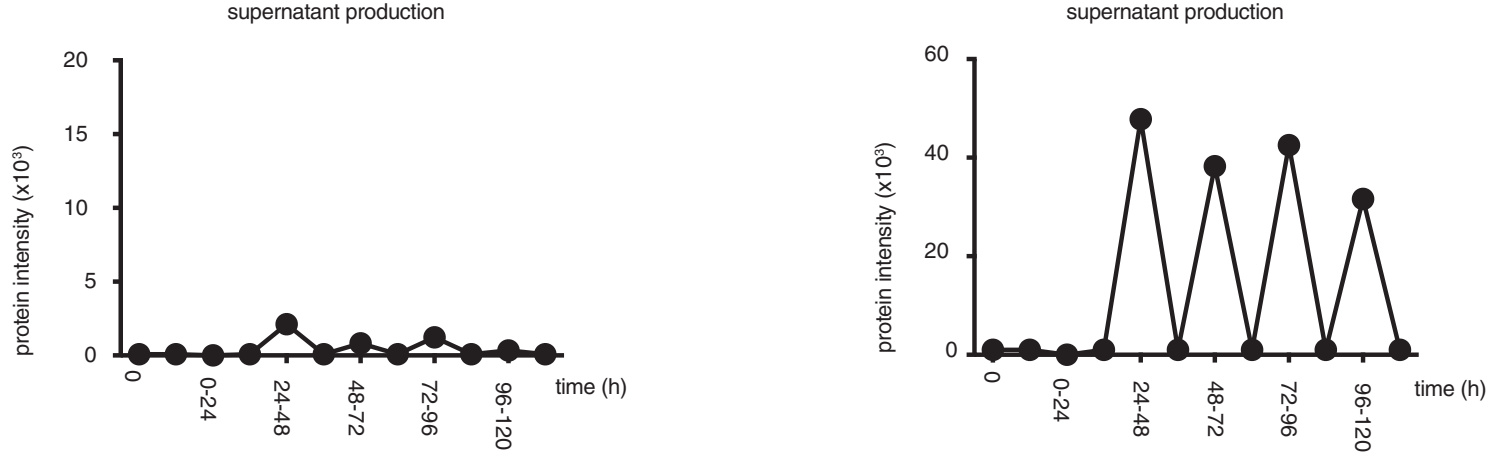

Fig. 1 IFN $\lambda 4$ accumulates intracellularly and is poorly secreted compared to other IFNs. Huh7 cells were mock-transfected (MV) or transfected with Myc-His-tagged expression vectors for IFN $\alpha$ and IFN $\lambda$ 1-4. a $48 \mathrm{~h}$ post-transfection, cell lysates (C) and supernatants (S) were collected. IFN proteins were detected by Myc-tag specific western blotting with the signal acquisition in the green channel of the Odyssey-CLx image system (Licor) (top panel). Without stripping, membranes were re-probed with an IFN $\lambda 4$-specific antibody with the signal acquisition in the red channel (bottom panel). In lysates from IFN $\lambda 1$ and IFN $\lambda 4$-expressing cells, several bands were detected representing different glycosylation forms of the proteins. Data are representative of $n$ $=3$ independent experiments. b, c IFN $\lambda 4$ and (d, e) IFN $\lambda 3$ total intracellular protein accumulation and daily supernatant production were measured over a 5-day period after transfection. Transfected cell lysates were harvested at the indicated time points after transfection. Cell-culture supernatants were collected every $24 \mathrm{~h}$ after a fresh medium was added to the transfected cells. IFN $\lambda 4$ and IFN $\lambda 3$ proteins were analyzed in cell lysates (C) and supernatants (S) by (b) IFN $\lambda 4$ - and (d) Myc-tag-specific western blotting, respectively. kDa, kilodalton. Relative accumulation and daily production of (c) IFN $\lambda 4$ and (e) IFN $\lambda 3$ were calculated from the band intensities in the western blots. Empty diamond, intracellular accumulation of IFN $\lambda 4$ and IFN $\lambda 3$. Filled circle, daily production of IFN $\lambda 4$ and IFN $\lambda 3$. Data are representative of $n=3$ independent experiments. Source data are provided as a Source Data file. 
a

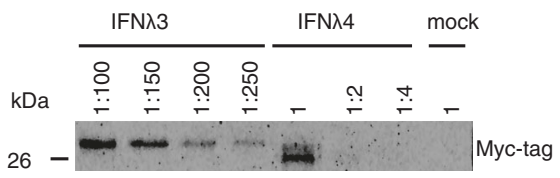

b

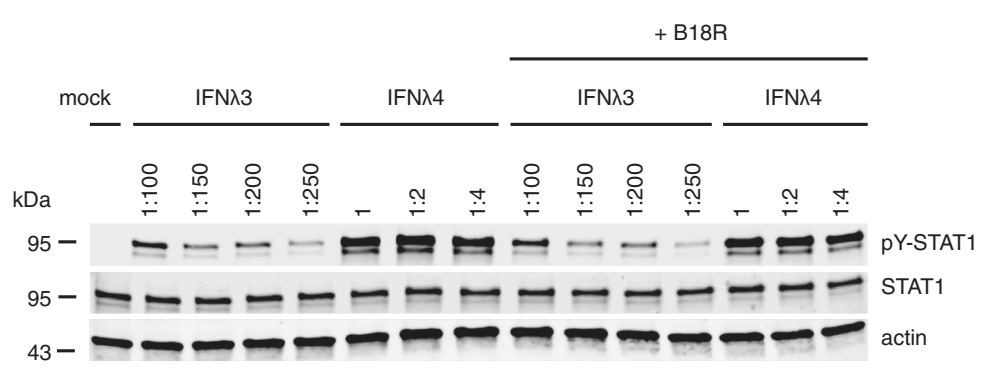

$\mathrm{kDa}$

C $130-\mathrm{D}-\boldsymbol{L}-\boldsymbol{-}-\boldsymbol{-}-\boldsymbol{-}-\boldsymbol{-}-\mathrm{pY}$-STAT2

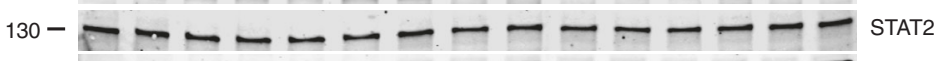

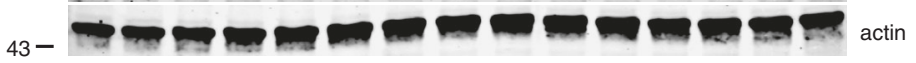
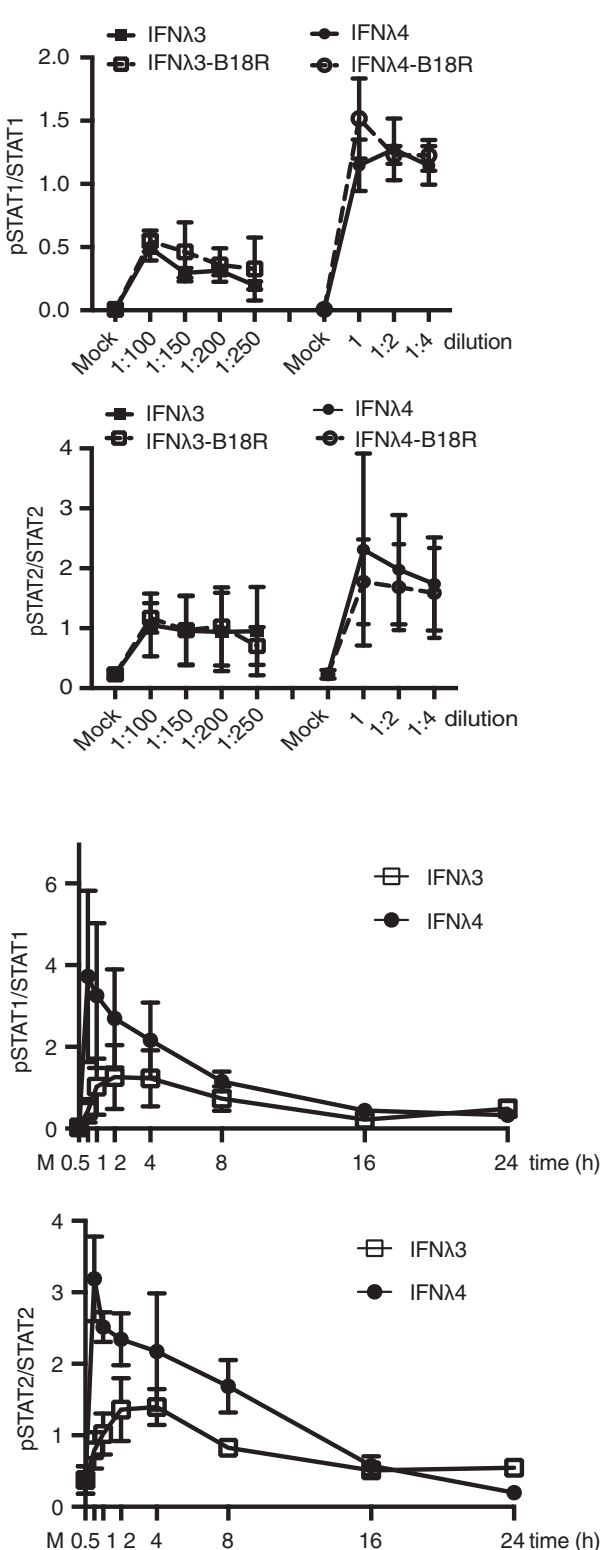

Fig. 2 IFN $\lambda 4$ is poorly secreted but very potently activates JAK-STAT signaling. a Huh7 cells were transfected with IFN $\lambda 3-M y c-H i s$ and IFN $\lambda 4-M y c-H i s$ plasmids or mock vector (mock) and cell-culture supernatants were collected $48 \mathrm{~h}$ later. IFN $\lambda 3$ and IFN $\lambda 4$ containing supernatants were diluted as indicated and $50 \mu \mathrm{l}$ each was analyzed by Myc-tag-specific western blotting. Data are representative of $n=3$ independent experiments. b, $\mathbf{c}$ Huh7-LR cells were seeded in a 48 -well plate and pre-treated with B18R $(500 \mathrm{ng} / \mathrm{ml})$ for $2 \mathrm{~h}$ or left untreated. After washing, cells were stimulated for 30 min with $150 \mu \mathrm{l}$ of IFN $\lambda 3$ and IFN $\lambda 4$ containing supernatants at the same dilutions shown in (a). Stimulated cells were lysed and analyzed for STAT activation by western blotting for (b) pY-STAT1 and STAT1 and (c) pY-STAT2 and STAT2 and actin as a loading control. The western blot signals were quantified and the ratios of phospho-STAT1/2 to total STAT1/2 were plotted. Results are presented as mean \pm SEM of $n=3$ independent experiments. Solid line with filled squares, IFN $\lambda 3$; dashed line with empty squares, IFN $\lambda 3-B 18 R$; solid line with filled circles, IFN $\lambda 4$; dashed line with empty circles, IFN $\lambda 4$ 4-B18R. d, e Huh7-LR cells were stimulated with $150 \mu$ of 1:100 diluted IFN $\lambda 3$ or undiluted IFN $\lambda 4$ containing supernatant for the indicated time or were mock-treated. STAT1 (d) and STAT2 (e) activation was assessed as described in $(\mathbf{b}, \mathbf{c})$. The western blot signals were quantified and the ratios of phospho-STAT1/2 to total STAT1/2 were plotted. Results are presented as mean \pm SEM of $n=3$ independent experiments. Solid line with empty squares, IFN $\lambda 3$; solid line with filled circles, IFN $\lambda 4$. Source data are provided as a Source Data file. 
a

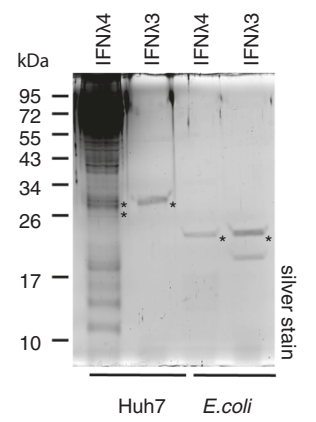

C b

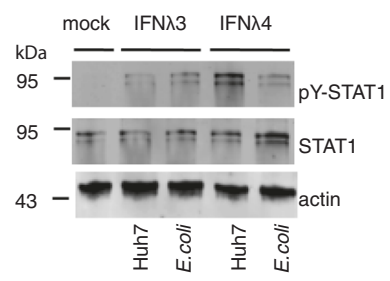

d

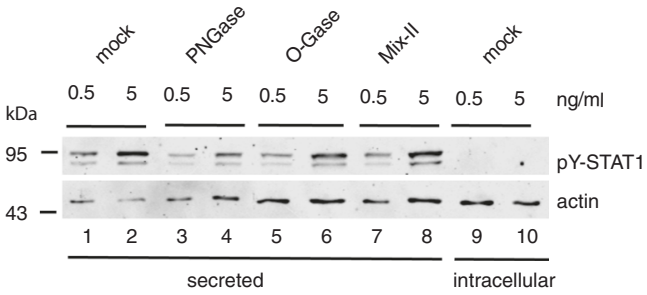

Fig. 3 IFN $\lambda 4$ activity is dependent on $\mathbf{N}$-linked glycosylation. a 50 ng each of IFN $\lambda 4$ and IFN $\lambda 3$ purified from Huh7 cells or $E$. coli were analyzed by $12 \%$ SDS-PAGE and quantified by silver staining. IFN $\lambda 4$ and IFN $\lambda 3$ proteins were indicated by an asterisk $\left(^{\star}\right)$. Huh7-produced IFN $\lambda 3$ and IFN $\lambda 4$ proteins are C-terminally tagged with Myc and $6 \times$ His, while E. coli-produced IFN $\lambda 3$ and IFN $\lambda 4$ proteins are $\mathrm{N}$ terminally tagged with $6 \times$ His. M, protein molecular weight marker; $\mathrm{kDa}$, kilodalton. Data are representative of $n=3$ independent experiments. b Huh7-LR cells were stimulated for 30 min with $8 \mathrm{ng} / \mathrm{ml}$ of IFN $\lambda 4$ or IFN $\lambda 3$ purified from Huh7 cells or E. coli or with supernatants collected $48 \mathrm{~h}$-post mock transfection (mock) in Huh7 cells. Cells were lysed and analyzed for STAT activation by western blotting for pY-STAT1, STAT1, and actin as a loading control. c $10 \mu$ lof purified IFN $\lambda 4$ from Huh7 cell-culture supernatant (secreted) was incubated alone in GlycoBuffer (mock) or was digested with a protein deglycosylation mix (Mix-I, an enzyme mix of PNGase $F$, O-glycosidase, $\beta-N$-acetyl glucosaminidase, $\beta 1-4$ galactosidase or $\alpha 2-3,6,8$ neuraminidase), N-linked glycosidase (PNGase F), O-link glycosidase (O-Gase), $\beta$ - $N$-acetylglucosminidase, $\beta-1-4$ galactosidase or neuraminidase at for $1 \mathrm{~h} 37^{\circ} \mathrm{C}$. A cell lysate of IFN $\lambda 4$-transfected-Huh7 cells was incubated in GlycoBuffer (mock) or digested with PNGase $\mathrm{F}$ for $1 \mathrm{~h}$ at $37^{\circ} \mathrm{C}$. IFN $\lambda 4$ proteins in the digested samples were detected by IFN $\lambda 4$-specific western blotting. $\mathrm{kDa}$, kilodalton. d Purified IFN $\lambda 4$ (secreted) and a cell lysate of IFN $\lambda 4$-transfected-Huh7 cells (intracellular) were mock-treated in GlycoBuffer or treated exactly as described in (c) with the indicated glycosidases (PNGase F, O-Gase and Mix-II, an enzyme mix of $\beta$ - $N$-acetylglucosminidase, $\beta-1-4$ galactosidase, neuraminidase). Huh7-LR cells were stimulated for $30 \mathrm{~min}$ at $37^{\circ} \mathrm{C}$ with the mock-treated or glycosidase-digested IFN $\lambda 4$ preparations at 0.5 and $5 \mathrm{ng} / \mathrm{ml}$. Stimulated cells were processed and analyzed as described in (b). Data are representative of $n=3$ independent experiments in (b-d). Source data are provided as a Source Data file.

indicating removal of $\mathrm{N}$-linked glycosylation. There was no clear change in molecular weight of IFN $\lambda 4$ upon treatment with other enzymes (Fig. 3c, lanes 4-7). Of note, PNGase F treatment of intracellular IFN $\lambda 4$ also shifted it to the same lower band, indicating that intracellular IFN $\lambda 4$ was also $N$-glycosylated (Fig. $3 \mathrm{c}$, lane 9).

To establish whether glycosylation affects IFN $\lambda 4$ activity, enzymatically pre-treated IFN $\lambda 4$ samples were used to stimulate Huh7-LR cells. PNGase F, but not the other enzymes, reduced the activity of IFN $\lambda 4$, indicating that $\mathrm{N}$-linked glycosylation is important for IFN $\lambda 4$ activity (Fig. 3d). Of note, intracellular IFN $\lambda 4$ did not induce pY-STAT1 activation despite the fact that it was $N$-glycosylated (Fig. 3c, d).

IFN $\lambda 4$ accumulates in the ER. The observation that intracellularly accumulated IFN $\lambda 4$ is $N$-glycosylated refutes the hypothesis that a defect in $\mathrm{N}$-glycosylation is responsible for the poor secretion of IFN $\lambda 4$. To explore other potential mechanisms for intracellular retention of IFN $\lambda 4$, we first set out to identify the subcellular compartment(s) where IFN $\lambda 4$ retention occurred. Immunofluorescence studies using IFN $\lambda 4$ antibodies together with an ER staining dye or an anti-Golgi antibody revealed that
IFN $\lambda 4$ colocalized both with ER membranes and the Golgi apparatus (Fig. 4a). Colocalization analysis showed preferential accumulation of IFN $\lambda 4$ in the ER. Next, we performed subcellular fractionation with IFN $\lambda 4$-transfected and IFN $\lambda 3$-transfected Huh7 cells. More than $50 \%$ of total IFN $\lambda 4$ was enriched in the ER or ER-PM (plasma membrane) fractions, whereas IFN $\lambda 3$ was enriched in the cytosolic (Cyto) fraction (Fig. 4b). Of note, intracellular IFN $\lambda 3$ was as potent as secreted IFN $\lambda 3$ (Supplementary Fig. $5 \mathrm{a}$, left panel). In contrast, intracellular IFN $\lambda 4$ was at least 100 times weaker than secreted IFN $\lambda 4$ irrespective of its subcellular location (Supplementary Fig. 5a, right panel). Together with the results from Fig. $4 \mathrm{a}$, this strongly suggests that intracellularly retained IFN $\lambda 4$ is not properly folded and remains inactive.

IFN $\lambda 4$ induces ER stress. The accumulation of unfolded $/ \mathrm{mis}$ folded proteins in the lumen of the ER induces the unfolded protein response (UPR) through the activation of the ER stress sensors protein kinase RNA-like endoplasmic reticulum kinase (PERK), inositol-requiring transmembrane kinase/endoribonuclease 1 (IRE1), and activating transcription factor-6 (ATF6) and their signaling cascades ${ }^{21,22}$. Therefore, we investigated whether these 
a
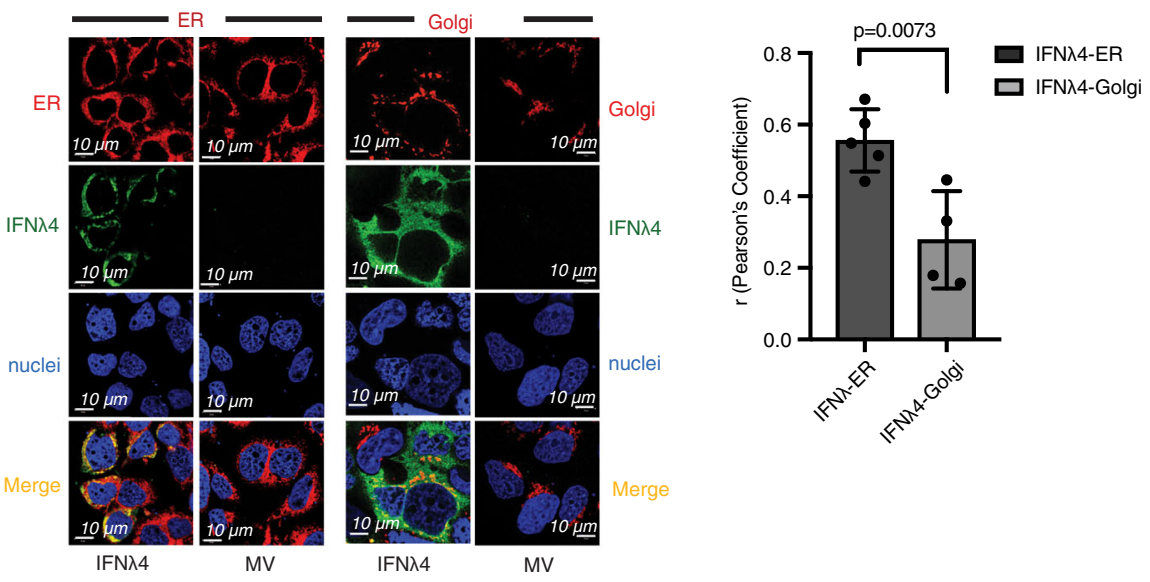

b

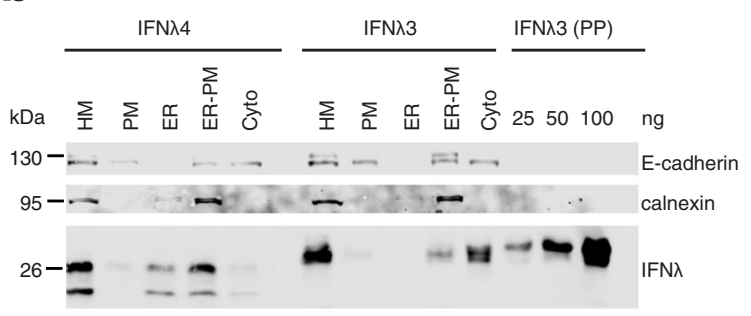

C

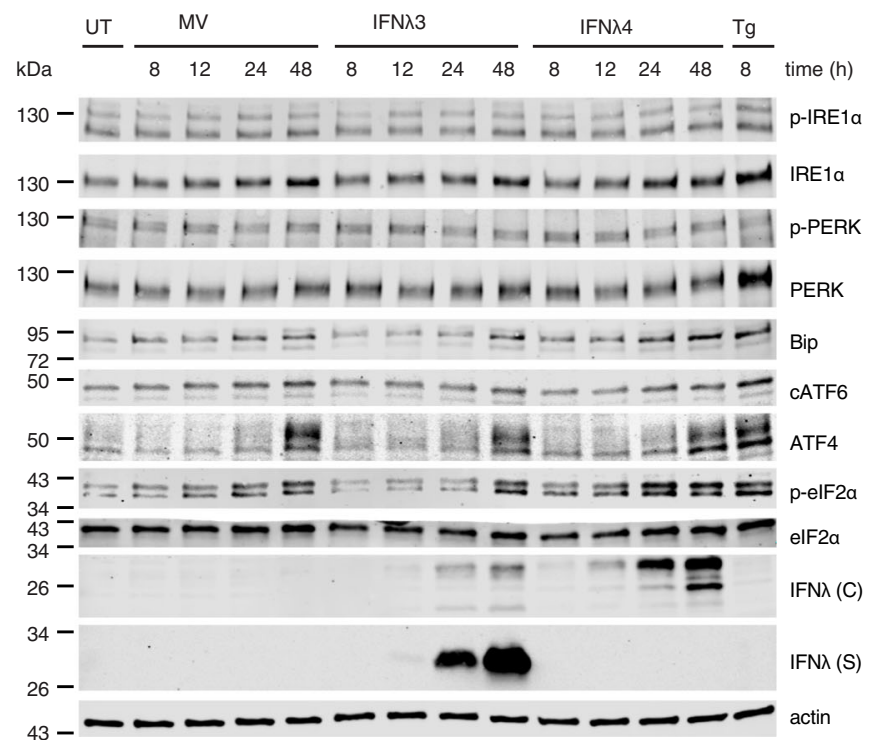

d
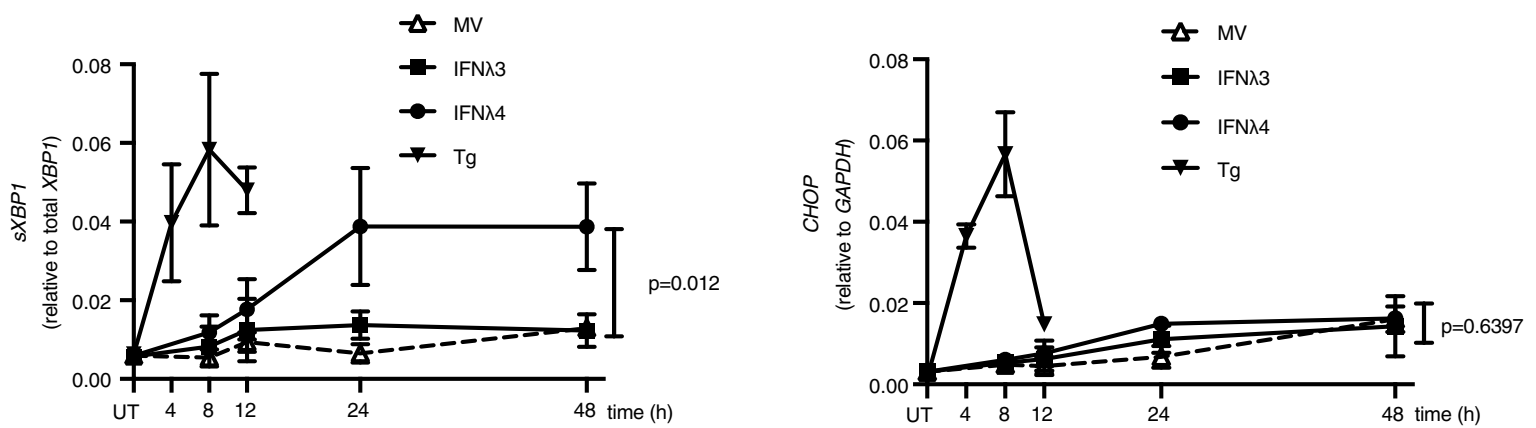

pathways were activated in cells transfected with IFN $\lambda 4$ expression plasmids. PERK, IRE1, ATF6, and eIF2 $\alpha$-activating transcription factor-4 (ATF4) were not significantly activated upon the expression of IFN $\lambda 4$ in Huh7 cells. Of note, treatment of Huh7 cells with the ER stress inducer Thapsigargin did also not affect these proteins. We, therefore, used phosphorylation of eIF $2 \alpha$ (p-eIF2 $\alpha$ ), splicing of

$\mathrm{X}$ box-binding protein (XBP1), and CHOP mRNA expression as indicators of ER stress induction in Huh7 cells. Transfection of IFN $\lambda 4$, but not IFN $\lambda 3$ or other IFN proteins, induced transient phosphorylation of eIF2 $\alpha$ with a peak at time point $24 \mathrm{~h}$ (Fig. $4 \mathrm{c}$ and Supplementary Fig. 5b) and splicing of XBP1, but did not induce CHOP (Fig. 4d and Supplementary Fig. 5c). Of note, 
Fig. 4 IFN $\lambda 4$ accumulates in the endoplasmic reticulum (ER) and causes ER stress. a Huh7 cells were transfected with IFN $\lambda 4$ encoding or mock expression vectors (MV) and processed $24 \mathrm{~h}$ later for immunofluorescence staining of ER (red, Cytopainter ER staining kit), Golgi (red, anti-Giantin antibody), IFN $\lambda 4$ (green, anti-IFN $\lambda 4$ antibody), and nuclei (blue, DAPI). Images are representative of $n=5$ independent experiments. Scale bars are $10 \mu \mathrm{m}$. Pearson's correlation of colocalization coefficients for IFN $\lambda 4$-ER (dark gray) and IFN $\lambda 4$-Golgi (light gray) were quantified as described in the "Methods" section separately for each IFN $\lambda 4$-expressing cell, $p=0.0073$, two-tailed unpaired $t$-test. b Huh7 cells were transfected with IFN $\lambda 4$ or IFN $\lambda 3$ expression vectors and homogenized $24 \mathrm{~h}$ later. Plasma membrane (PM), ER, plasma-ER associated membrane-associated (ER-PM) and cytosolic (Cyto) fractions were enriched from the cell homogenate as described in the "Methods" section. $2 \mu$ l of each fraction and dilutions of purified IFN $\lambda 3$ as a protein standard were analyzed by western blotting for the presence of IFN $\lambda 4$ and IFN $\lambda 3$ (using anti-Myc-tag antibody) and for E-cadherin and calnexin as markers for PM and ER, respectively (upper panel). The IFN $\lambda$ protein distribution in the fractions was calculated from the western blot data with the IFN $\lambda 4$ (black) and IFN $\lambda 3$ (light gray) signal in the total HM set to $100 \%$ (lower panel). kDa, kilodalton. c Huh7 cells were transfected with Myc-His-tagged IFN $\lambda 3$ and IFN $\lambda 4$ expression vectors or a mock vector (MV) or left untreated (UT). Cell lysates and cell-culture supernatants were collected at the indicated time points. Cell lysates were analyzed by western blotting for the ER stress markers IRE1 $\alpha$, phosphor- IRE1 $\alpha$, PERK, phosphor-PERK, Bip, cleaved ATF6 (cATF6), ATF4, phospho-elF2 $\alpha$, and elF2 $\alpha$ using marker-specific antibodies as well as intracellular IFNs (IFNs(C)) using an anti-Myc-tag antibody. IFN proteins in the supernatants (IFNs(S)) were also detected with an anti-Myc-tag antibody. Cells treated with $2 \mu \mathrm{M}$ Thapsigargin (Tg) for $8 \mathrm{~h}$ served as a positive ER stress control. d Total cellular RNA was harvested from Huh7 cells transfected or treated as described in (c) at the indicated time points. Spliced mRNA of the ER stress marker sXBP1 (left panel) and total mRNA of CHOP (right panel) were analyzed by RT-qPCR as described in the "Methods" section. sXBP1 levels are shown as relative expression to mRNA level of total XBP1. CHOP mRNA expression was calculated relative to that of the housekeeping gene GAPDH. Results are presented as mean \pm SEM of $n=3$ independent experiments. The dashed line with empty triangles, MV; Solid line with filled squares, IFN $\lambda 3$; solid line with filled circles, IFN $\lambda 4$; solid line with filled triangles, Tg (thapsigargin). Source data are provided as a Source Data file.

stimulation of cells with supernatant of IFN $\lambda 4$ did not induce XBP1 splicing (Supplementary Fig. 5c), suggesting that ER stress is caused by misfolded endogenous IFN $\lambda 4$ and not by the small amounts of correctly folded and secreted IFN $\lambda 4$. We also quantified induction of $s X B P 1$ and $C H O P$ mRNA in doxycycline-inducible HepG2 cell lines that stably express GFP-tagged IFN $\lambda 4$ (IFN $\lambda 4-G F P$ ) or its truncated non-functional form IFN $\lambda 4$ p131-GFP. Indeed, wild-type, but not truncated IFN $\lambda 4$ induced both the early and late UPR, $s X B P 1$, and CHOP in HepG2 cells (Supplementary Fig. 5d, e).

We conclude that IFN $\lambda 4$ is not properly folded, is retained in the ER, and induces ER stress.

Sendai virus infection induces IFN $\lambda 4$ expression and ER stress. It has been previously reported that IFN $\lambda 4$ is only transiently and weakly expressed upon viral infections or stimulation of cells with polyI: $C^{8,11-13}$. Thus, we wanted to confirm the findings obtained in cells transfected with IFN $\lambda 4$ expression plasmids and further explore the impact of IFN $\lambda 4$ on the cellular response to Sendai virus $(\mathrm{SeV})$ infection. We first infected the lung epithelial cell line A549 with $\mathrm{SeV}$, and could detect IFN $\lambda 4$ expression both at the mRNA and the protein level (Supplementary Fig. 6). Of note, SeV infection-induced glycosylated and non-glycosylated IFN $\lambda 4$ isoforms confirming our findings in cells transfected with IFN $\lambda 4$ expression vectors (Supplementary Fig. 6b). The poor secretion of IFN $\lambda 4$ observed in the transfection system (Figs. 1 and 2) was also confirmed. IFN $\lambda 4$ was only detectable in cell lysates but not in the supernatants (Supplementary Fig. 6b).

To further study the impact of endogenous-induced IFN $\lambda 4$ on the host response to $\mathrm{SeV}$, we made use of liver-derived organoids (Supplementary Fig. 7) 23,24 . Three liver organoid cell lines of the IFN $\lambda 4$-expressing genotype IFNL4- $d G$ (B16, U15, U12) and three of the IFN $\lambda 4$ deficient genotype IFNL4-TT/TT (U16, nt5, B13) were infected with SeV. Viral replication, IFN $\beta, \operatorname{IFN} \lambda 1,-2 / 3$ and -4 induction and ISG expression were not different between IFN $\lambda 4$ producing $(d G)$ and non-producing (TT) organoids (Fig. 5a). This was not due to impaired or defective IFN $\lambda 4$ protein production, as demonstrated by the detection of IFN $\lambda 4$ protein in the membrane fraction of $d G$ but not $T T$ organoids (Fig. 5b). Furthermore, the apparent molecular weight of the IFN $\lambda 4$ proteins was similar to that in A549 cells at $12 \mathrm{~h}$, demonstrating the IFN $\lambda 4$ was correctly glycosylated in organoids of the $d G$ genotype.

We next assessed whether $\mathrm{SeV}$-induced endogenous IFN $\lambda 4$ also induced ER stress. Indeed, $s X B P 1$ mRNA expression was upregulated in correlation with IFN $\lambda 4$ expression in the IFN $\lambda 4$ expressing $(d G)$ but not the non-expressing (TT) organoids (Fig. 5c). We conclude that IFN $\lambda 4$ is induced upon $\mathrm{SeV}$ infection in $d G$ organoids, induces ER stress, but has no detectable impact on $\mathrm{SeV}$ replication or the induction of ISGs.

Impact of IFN $\lambda 4$ genotype on global gene expression. To further study the impact of $\mathrm{SeV}$-induced IFN $\lambda 4$ on the cellular response to viral infection, we performed RNAseq on liver organoids with a $d G$ genotype (B20, nt115, U15) and with a TT genotype (nt5, U16, U19). From each organoid, we profiled the uninfected organoids at time point $0 \mathrm{~h}$ (pre-infection) and $12 \mathrm{~h}$ (mock), and from SeV-infected (SeV) organoids at time point 12 $\mathrm{h}$. The $12 \mathrm{~h}$ time point was chosen because we observed the peak of IFN $\lambda 4$ expression at this time (Fig. 5a). Multidimensional scaling (MDS) of the transcriptomic profiles revealed a clear separation between $\mathrm{SeV}$-infected and uninfected samples (Supplementary Fig. 8a). By contrast, among both the infected and the uninfected samples, no clear separation was observed between the IFN $\lambda 4$ genotypes (Supplementary Fig. 8a). To identify transcriptomic changes induced by $\mathrm{SeV}$ infection, we performed a differential expression analysis between $\mathrm{SeV}$-infected and uninfected (pre-infection and mock) samples. We found that $\mathrm{SeV}$ infection-induced changes in the expression levels of 4649 and 3306 genes in the $d G$ and the $T T$ genotypes, respectively, including a significant enrichment of 2983 genes commonly altered in both genotypes (enrichment factor $=2.55, p<2.2 \mathrm{e}-16$, hypergeometric test, Supplementary Fig. 8b). Indeed, the overall gene expression changes induced by $\mathrm{SeV}$ were highly similar in the two IFN $\lambda 4$ genotypes $(r=0.93$, Pearson correlation, $p<2.2 \mathrm{e}$ -16 , Supplementary Fig. $8 b$ ). This was also reflected at the level of biological pathways as determined by pathway enrichment analysis (Supplementary Fig. 8c; Supplementary Data 1 and 2). Since the molecular analysis revealed a dG genotype-specific induction of ER stress, we specifically interrogated the RNAseq data for differences in regulation of genes associated with response to ER stress. Indeed, gene set enrichment analysis revealed that the pathway "GO-Response_To_Endoplasmic_Reticulums_Stress" was positively enriched in organoids of $d G$ genotype, although the difference did not reach statistical significance. Nevertheless, the regulation of the corresponding genes was stronger in the organoids of the $d G$ genotype (Supplementary Fig. 8d) consistent with the induction of an IFN $\lambda 4$-dependent ER stress upon viral infection. 
a
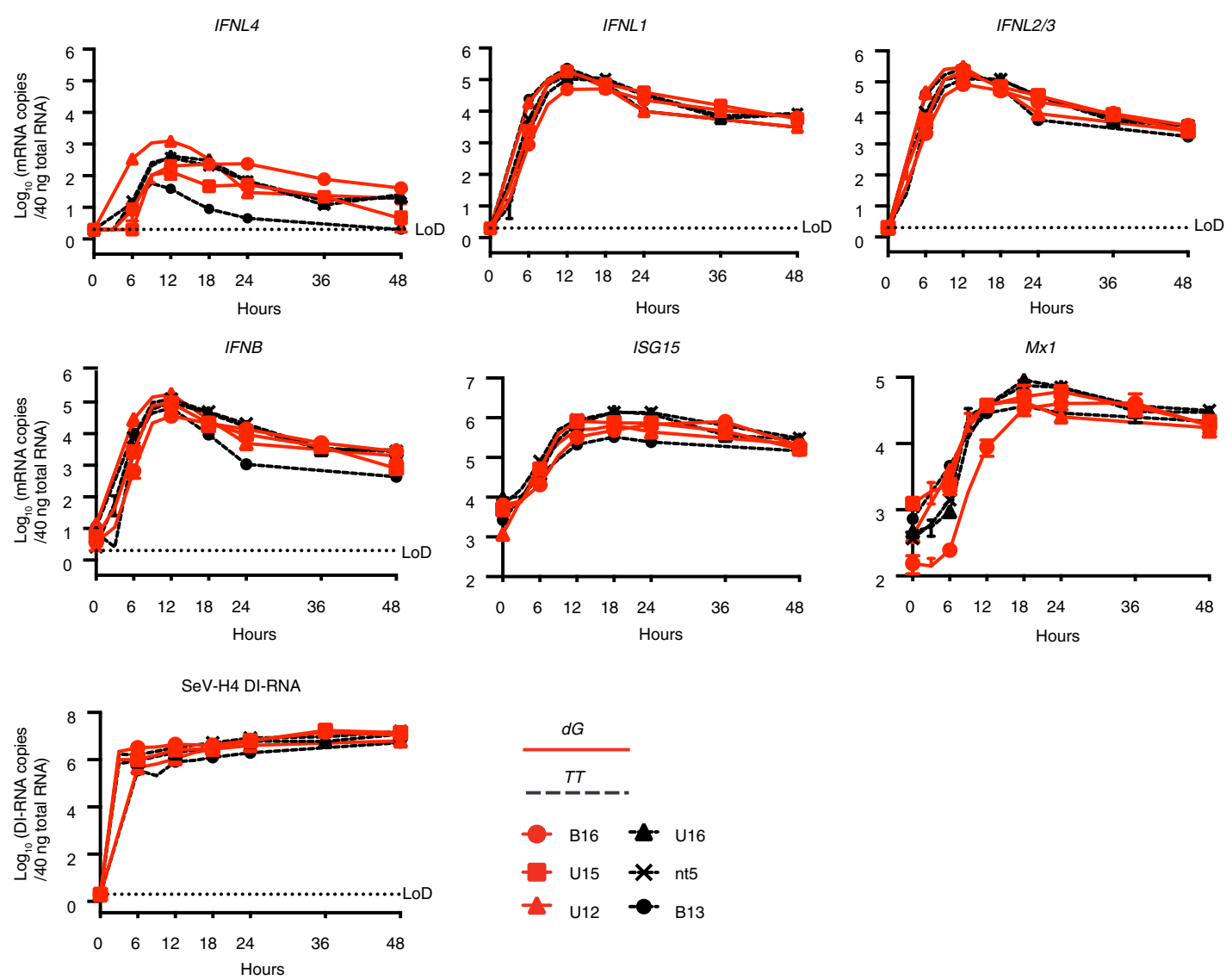

b

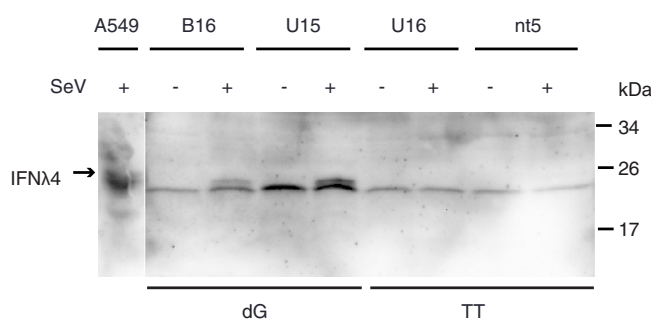

C

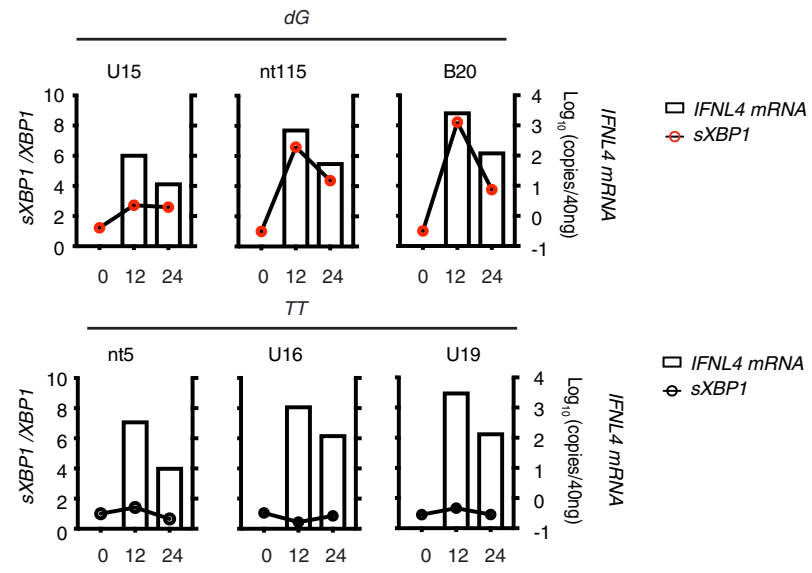

IFN $\lambda 4$ expression inhibits $\mathrm{HCV}$ peptide-specific $\mathrm{CD8}^{+} \mathrm{T}$ cell activation. Cytosolic antigens presented by MHC-I are primarily derived from proteasomal cleavage of proteins into peptides that are then imported into the ER and loaded onto newly synthesized MHC-I ${ }^{25}$. Thus, we hypothesized that the IFN $\lambda 4$-induced ER stress could interfere with HCV antigen presentation, and thereby reduce the activation of $\mathrm{HCV}$ specific $\mathrm{CD}^{+} \mathrm{T}$ cells. To address this question, we made use of a unique in vitro cell coculture system consisting of subgenomic HCV replicon cells stably transduced with HLA-A2 $\left(\mathrm{Huh} 7_{\mathrm{A} 2} \mathrm{HCV}_{\mathrm{EM}}\right)$ and an HLA-matched $\mathrm{HCV}$-specific $\mathrm{CD} 8^{+}$ $\mathrm{T}$ cell clone $\mathrm{e}^{26}$. 
Fig. 5 IFN $\lambda 4$ is induced upon viral infection in liver-derived organoids. Liver-derived organoid cultures of the dG (B16, U15, U12) and TT (U16, nt5, B13) genotype were infected with Sendai virus $\mathrm{H} 4$ at a $\mathrm{MOI}=10$ as described in the "Methods" section. a Organoids were harvested at 3, 6, 9, 12, 18, 24, 36, and $48 \mathrm{~h}$ after $\mathrm{SeV}$ inoculation. Uninfected organoids were harvested at the time of SeV inoculation and used as time point $0 \mathrm{~h}$. Total cellular RNA was extracted and analyzed by RT-qPCR for the expression of SeV DI-RNA and mRNA expression of interferons (IFNB, IFNL1, IFNL2/3, IFNL4) and the ISGs MxI and ISG15. Results are presented as mean \pm SEM of biological replicates ( $n=3$ for B16, U15, U16, and nt5, $n=1$ for U12 and B13). For better visualization, the data point symbols of the 3 and $9 \mathrm{~h}$ time points have been omitted from the graphs. Red, $d G$ organoids; black, TT organoids; dotted line, lower limit of detection (LoD); negative data points and those below LoD are displayed at LoD. b Some SeV-infected organoids (B16, U15, U16, nt5) were harvested at 12 h post-infection and processed for IFN $\lambda 4$-specific western blot analysis as described in the "Methods" section. M, molecular size marker. Data are presented from one representative experiment. c Three organoid cultures each of the $d G(B 20, n t 115$, U15) and TT (nt5, U16, U19) genotype were infected with Sendai virus $\mathrm{H} 4(\mathrm{MOI}=10)$. Total cellular RNA was extracted from infected cells at the indicated time points and analyzed for the mRNA expression of IFNL4 and sXBP1 mRNA. SXBP1 levels are shown as the ratio of the spliced (s)XBP1 mRNA to total XBP1 RNA. The ratio at the time point 0 of each organoid line was set to 1. IFNL4 levels were expressed as copy numbers per $40 \mathrm{ng}$ of total RNA. Open bars, IFNL4 mRNA; lines with red circles, sXBP1 mRNA in $d G$ organoids; lines with black circles, sXBP1 mRNA in TT organoids. Source data are provided as a Source Data file.

We tested the impact of ER stress on T cell response in this system by Thapsigargin treatment of the $\mathrm{Huh}_{\mathrm{A} 2} \mathrm{HCV}_{\mathrm{EM}}$ (Supplementary Fig. 9a, b). As expected, Thapsigargin induced XBP1 splicing and indeed, $\mathrm{HCV}$-specific $\mathrm{CD}^{+} \mathrm{T}$ cell activation was significantly reduced. Next, Huh7 ${ }_{\mathrm{A} 2} \mathrm{HCV}_{\mathrm{EM}}$ cells were transfected with expression plasmids for IFNa, IFN $\lambda 1$, IFN $\lambda 3$, and IFN $\lambda 4$. Consistent with our previous results, IFN $\lambda 4$ was retained in the cells and induced ER stress (Supplementary Fig. 10a, b). Consequently, we observed a significant reduction of $\mathrm{CD}^{+} \mathrm{T}$ cell activation by $\mathrm{Huh}_{\mathrm{A} 2} \mathrm{HCV}_{\mathrm{EM}}$ cells expressing IFN $\lambda 4$, but not by cells transfected with IFN $\lambda 1$ or IFN入3 (Fig. 6a). This was not due to reduced expression of HLA-2A (Fig. 6b), and also not caused by a stronger inhibition of $\mathrm{HCV}$ replication in IFN $\lambda 4$-transfected cells compared to IFN $\lambda 1$ - or IFN $\lambda 3$ transfected cells (Fig. 6c). Furthermore, treatment of $\mathrm{Huh}_{\mathrm{A} 2} \mathrm{HCV}_{\mathrm{EM}}$ cells with IFN $\lambda 3$ or IFN $\lambda 4$ did not induce an ER stress response in $\mathrm{Huh}_{\mathrm{A} 2} \mathrm{HCV}_{\mathrm{EM}}$ and had no impact on $\mathrm{T}$ cell activation (Supplementary Fig. 9a, b). To further test the hypothesis of IFN $\lambda 4$ interference with endogenous peptide loading on MHC-I, we investigated whether the $\mathrm{T}$ cell response could be rescued by exogenous loading of an HCV peptide to the replicon cells. To this end, we used another replicon cell clone ( $\left.\mathrm{Huh} 7_{\mathrm{A} 2} \mathrm{HCV}\right)$ presenting a mismatched epitope that does not induce $\mathrm{T}$ cell activation but is otherwise identical to $\mathrm{Huh}_{\mathrm{A} 2} \mathrm{HCV}_{\mathrm{EM}}$ cells ${ }^{26}$. As expected, IFN $\lambda 4$ had no impact on $\mathrm{T}$ cell activation in this setting (Fig. 6d). Collectively, these results provide strong evidence that IFN $\lambda 4$ induced ER stress impairs endogenous processing and MHC-I loading of HCV antigens, and thereby inhibits HCV-specific $\mathrm{CD} 8^{+} \mathrm{T}$ cell responses.

IFN $\lambda 4$-TT expression does not inhibit $\mathrm{HCV}$ peptide-specific $\mathrm{CD8}^{+} \mathrm{T}$ cell activation. Finally, we explored the impact of expressing the non-functional TT isoform of IFN $\lambda 4$ on HCVspecific $\mathrm{T}$ cell activation. Cells transfected with an IFN $\lambda 4$-TT expression plasmid showed no activation of the Jak-STAT pathway and no ER stress response (Fig. 7a, b and Supplementary Fig. 11). Interestingly, this non-functional IFN $\lambda 4$ is secreted (Fig. 7a). Contrary to IFN $\lambda 4$, expression of IFN $\lambda 4$-TT in $\mathrm{Huh}_{\mathrm{A} 2} \mathrm{HCV}_{\mathrm{EM}}$ cells did not inhibit HCV-specific $\mathrm{CD}^{+} \mathrm{T}$ cell responses (Fig. $7 \mathrm{c}$ ). These results demonstrate a genotype-specific inhibition of $\mathrm{HCV}$-specific $\mathrm{T}$ cell responses that can explain the association of the IFNL4-dG genotype with viral persistence.

\section{Discussion}

A number of genetic variants in the IFN-lambda (IFNL) gene locus has been associated with the outcome of HCV infection. For example, multiple SNPs in the IFNL3 have been shown to regulate IFNL3 transcription or translation ${ }^{27-31}$. In a seminal discovery, IFN $\lambda 4$ has been identified as the molecular link between the various genetic variants of the IFN-lambda (IFNL) gene locus and spontaneous and treatment-induced clearance of $\mathrm{HCV}$ leading to the so-called "IFN $\lambda 4$ paradox" $8,10,32$. Individuals with a functional IFNL4 gene show an impaired host defense during acute hepatitis $\mathrm{C}$ and often become chronically infected ${ }^{2-7}$, despite the fact that cell-culture experiments demonstrate a strong antiviral activity of IFN $\lambda 4$ against $\mathrm{HCV}$ and corona virus $^{10}$. Moreover, IFN $\lambda 4$ signals through the same receptor that other members of type III IFN do, and its biochemical characteristics are highly comparable $\mathrm{e}^{10-12,15}$. A striking difference to the other IFN $\lambda s$ is the poor secretion of IFN $\lambda 4^{8,10,11,14}$. Therefore, we performed biochemical and immunological studies to explore whether there are differences between IFN $\lambda 4$ and other IFNs in regard to biosynthesis, secretion, induction of JAK-STAT signaling, and antigen presentation that could explain the negative impact of IFN $\lambda 4$ on the immune response to the virus.

In our long-term expression experiments over 5 days, IFN $\lambda 4$ was barely detectable in the cell-culture supernatant at all time points (Fig. 1). Nevertheless, the small amounts of IFN $\lambda 4$ were highly potent (Fig. 2). Using purified proteins, we estimate that IFN $\lambda 4$ is 28 times more potent per ng of protein compared to IFN $\lambda 3$. The reasons for this striking difference in potency remain to be explored. Interestingly, Huh7-produced IFN $\lambda 4$ that is properly glycosylated is the most potent, while $E$. coli-produced IFN $\lambda 4$ and IFN $\lambda 3$ are equally active as Huh7-produced IFN $\lambda 3$. We extended these observations by comparing IFN $\lambda 4$ activity pre- and post-enzymatic removal of $\mathrm{N}$-linked sugar residue, demonstrating that glycosylation is important to preserve biological potency of IFN $\lambda 4$, which has also been demonstrated with other cytokines and receptors ${ }^{33-35}$.

Immunofluorescence staining and subcellular fractionation analysis revealed that IFN $\lambda 4$ is retained in the ER (Fig. 4). It is well known that for some proteins, glycosylation is an important step for entering the secretory pathway. However, the absence of IFN $\lambda 4$ glycosylation cannot be the main reason for poor secretion, since intracellular retained IFN $\lambda 4$ seems to be correctly glycosylated (Fig. 3c). Rather, we believe that IFN $\lambda 4$ is not properly folded. This hypothesis is supported by the observation that even correctly glycosylated but intracellularly retained IFN $\lambda 4$ cannot induce STAT1 phosphorylation (Fig. 3d). Since proteins have to pass a "qualitycontrol" check before being transported from ER through the protein secretory pathway ${ }^{36,37}$, misfolding in the ER could well explain the retention of IFN $\lambda 4$ in the ER. Like other misfolded glycoproteins, improperly folded IFN $\lambda 4$ would have to cycle through the "refolding" process before it reaches its native conformation. Only the small fraction of correctly folded protein would then be secreted. The model is consistent with our observation that ER-accumulated IFN $\lambda 4$ induces UPR in Huh7, HepG2, and HCV replicon ( $\left.\mathrm{Huh}_{\mathrm{A} 2} \mathrm{HCV}_{\mathrm{EM}}\right)$ cells by stimulating XBP1 mRNA splicing. Many of the ER stress response markers were not strongly induced in the Huh7 cells by IFN $\lambda 4$, but this was also the case for thapsigargin (Fig. 4c, d). We, 
a
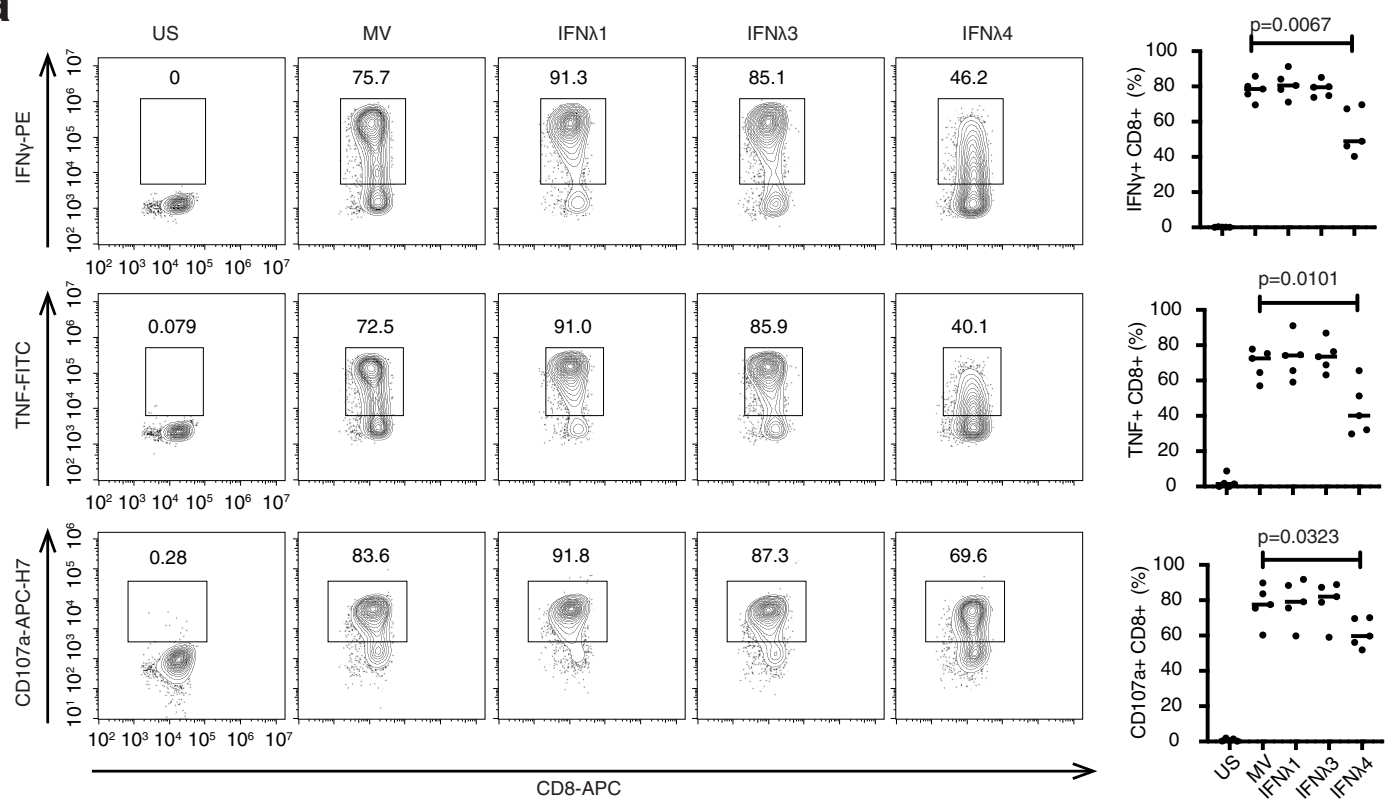

b

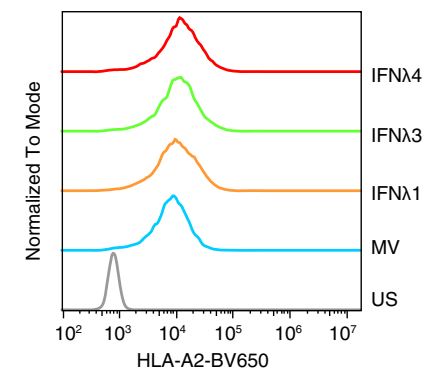

C

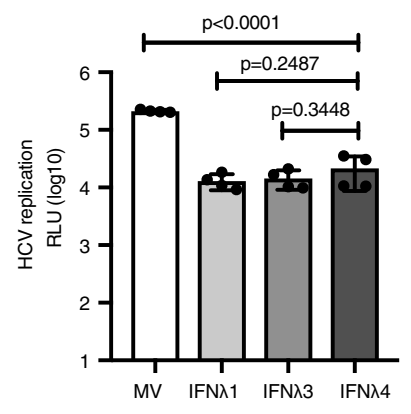

d
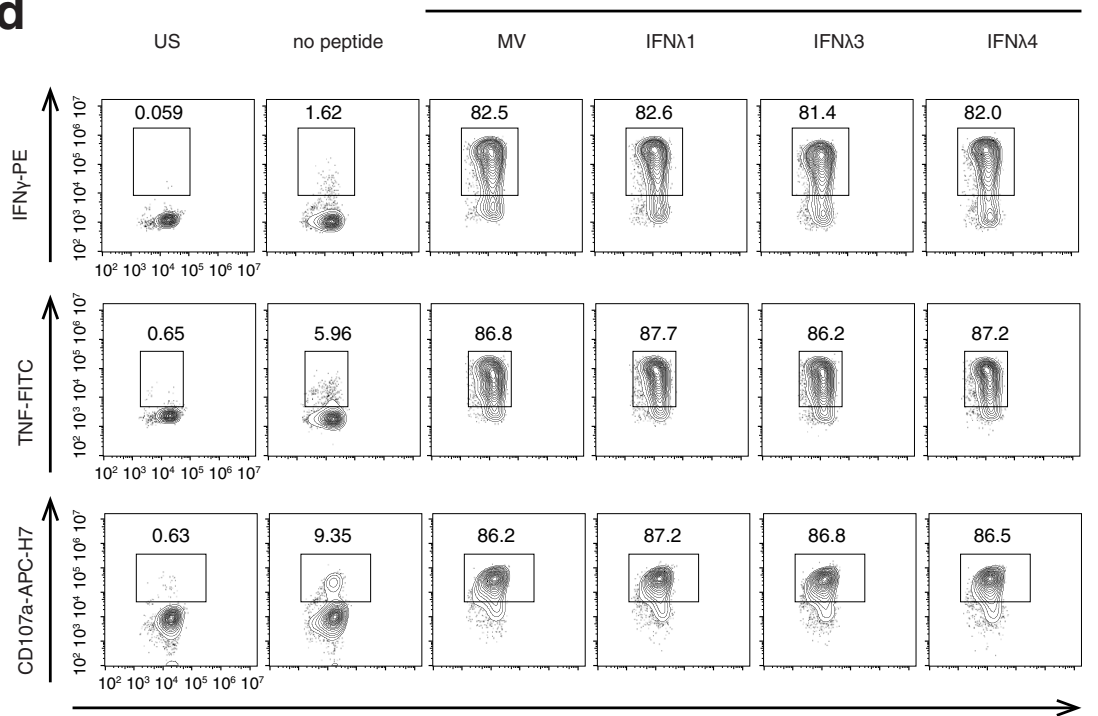

CD8-APC
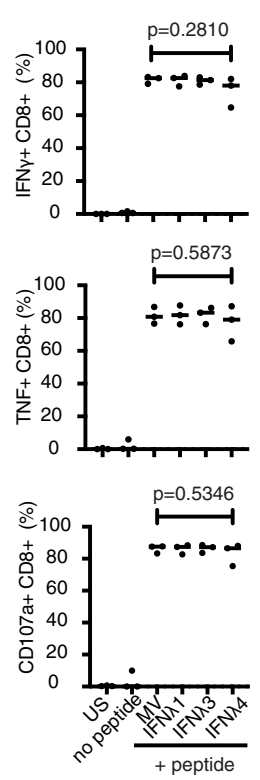

therefore, think that the weak induction of these ER stress response markers rather reflects an intrinsic property of the Huh7 cells than a limited ER stress-inducing activity of IFN $\lambda 4$. Furthermore, ER stress was not only observed in overexpression systems, but also when IFN $\lambda 4$ was expressed from the cellular genome in reaction to $\mathrm{SeV}$ infection. The fact that XBP1 mRNA splicing upregulated in viral- infected organoids of $d G$ genotype, but not of TT genotype (Fig. 5c), proves that IFN $\lambda 4$ protein expression is causing ER stress.

$\mathrm{SeV}$-induced IFN $\lambda 4$ expression in organoids also allowed us to explore the impact of IFN $\lambda 4$ on global gene expression in a physiological context. As expected, multidimensional scaling (MDS) revealed a clear separation between $\mathrm{SeV}$-infected and 
Fig. 6 IFN $\lambda 4$ inhibits $\mathbf{H C V}$ peptide-specific CD8 ${ }^{+} \mathbf{T}$ cell activation. a Huh7 ${ }_{\mathrm{A} 2} \mathrm{HCV} \mathrm{EM}_{\mathrm{E}}$ cells were transfected with expression vectors encoding IFN $\lambda 1$, IFN $\lambda 3$, IFN $\lambda 4$ or a mock vector (MV) and $48 \mathrm{~h}$ later were cocultured with a NS5B $2594-2602$-specific $\mathrm{CD}^{+} \mathrm{T}$ cell clone for $5 \mathrm{~h}$. Intracellular IFN $\gamma$ and TNF production, and CD107a mobilization were then analyzed by flow cytometry as described in the "Methods" section. US, unstimulated CD8 ${ }^{+}$T cell control. IFN $\lambda 4$ expression inhibits $\mathrm{CD}^{+} \mathrm{T}$ cell activation as measured by the frequency of IFN $\gamma$-, TNF- and CD107a-positive CD8 ${ }^{+} \mathrm{T}$ cells (left panel). Data of $n=5$ independent experiments were

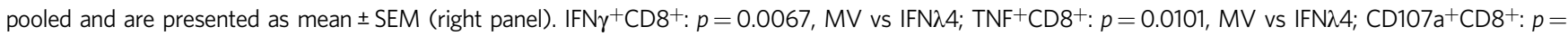
$0.0323, \mathrm{MV}$ vs IFN $\lambda$ 4, all by two-tailed unpaired $t$-test. $\mathbf{b}$ Surface expression of HLA-A2 is not affected by IFN expression in vector-transfected Huh7 ${ }_{\mathrm{A} 2} \mathrm{HCV}_{\mathrm{EM}}$ cells as analyzed by HLA-A2 BV650-specific flow cytometry. US, unstained control. Data are representative of $n=3$ independent experiments. c Inhibition of viral replication was measured in IFN-expression vector-transfected compared to mock vector (MV) transfected $\mathrm{Huh}_{\mathrm{A} 2} \mathrm{HCV}_{\mathrm{EM}}$ cells by luciferase activity. Results are expressed as mean \pm SEM of $n=4$ biological replicates from $n=2$ independent experiments. $p<0.0001$, MV vs IFN $\lambda 4 ; p=0.2487$, IFN $\lambda 1$ vs IFN $\lambda 4 ; p=0.3448$, IFN $\lambda 3$ vs IFN $\lambda 4$, two-tailed unpaired $t$-test. $\mathbf{d}$ Peptide-mismatched Huh7 ${ }_{\mathrm{A} 2} \mathrm{HCV}$ cells were transfected exactly as described in (a). The transfected cells were then loaded with exogenous $\mathrm{NS5B}_{2594-2602}$-ALYDVVTKL peptide before coculture with $\mathrm{NS5B}_{2594-2602}$-specific CD8 ${ }^{+} \mathrm{T}$ cells. Coculture and flow cytometry analysis were performed exactly as described in (a) except that the right panel shows the results of mean $\pm \mathrm{SEM}$ from $n=3$ independent experiments. IFN $\gamma^{+} \mathrm{CD} 8^{+}: p=$ $0.2810, \mathrm{MV}$ vs IFN $\lambda 4$; TNF ${ }^{+} \mathrm{CD}^{+}: p=0.5873, \mathrm{MV}$ vs IFN $\lambda 4$; $\mathrm{CD} 107 \mathrm{a}^{+} \mathrm{CD}^{+}: p=0.5346, \mathrm{MV}$ vs IFN $\lambda 4$, all by two-tailed unpaired $t$-test. Source data are

provided as a Source Data file.

uninfected samples, mainly due to the induction of interferonstimulated genes (ISGs). On the other hand, $\mathrm{SeV}$ infectioninduced highly similar gene sets in both $d G$ and $T T$ organoids. Nevertheless, the upregulation of ER stress-related genes was stronger in organoids of the $d G$ genotype, although the difference was not significant (Supplementary Fig. 8d). We conclude that the small amount of IFN $\lambda 4$ expression in the context of viral infection does not significantly alter the overall transcriptional response induced by the very potent type I IFN system. However, this does not rule out that intracellular IFN $\lambda 4$ retention causes ER stress and thereby affects protein trafficking.

The ER plays also an important role in the loading of viral antigen peptides onto the MHC class I complex. To test whether IFN $\lambda 4$-induced ER stress could interfere with HCV antigen presentation, we used a unique in vitro cell coculture system consisting of sub-genomic HCV replicon cells stably transduced with HLA-A2 (Huh7 ${ }_{\mathrm{A} 2} \mathrm{HCV}_{\mathrm{EM}}$ ) and an HLA-matched HCV-specific $\mathrm{CD}^{+} \mathrm{T}$ cell clone ${ }^{26}$. In this system, IFN $\lambda 4$ expression in the antigen-presenting replicon cells impaired the $\mathrm{CD}^{+} \mathrm{T}$ cell response. This was not due to inhibition of HCV replication or reduced cell surface expression of MHC class I molecules. Furthermore, we could rescue the $\mathrm{CD} 8^{+} \mathrm{T}$ cell response by loading HCV peptide exogenously. This demonstrates that the negative effect of IFN $\lambda 4$ on the CD ${ }^{+} \mathrm{T}$ cell response is not mediated by direct inhibition of $\mathrm{CD}^{+} \mathrm{T}$ cells, but by causing reduced antigen presentation. Moreover, when transfecting a plasmid expressing the non-functional IFN $\lambda 4$-TT variant in the HCV replicon cells, $\mathrm{CD}^{+} \mathrm{T}$ cell activity was not inhibited. Based on these observations, we propose that the IFN $\lambda 4$ paradox can be explained by the negative impact of IFN $\lambda 4$ on $\mathrm{HCV}$ antigen presentation to immune cells. Interestingly, previous studies have shown decreased numbers of CD8 ${ }^{+} \mathrm{T}$ cells and $\mathrm{CD} 163^{+}$macrophages in liver biopsies from patients of the IFN $\lambda 4$ producing genotype ${ }^{38}$, and decreased degranulation activity in freshly isolated $\mathrm{CD} 3^{+} \mathrm{CD} 56^{-} \mathrm{T}$ and $\mathrm{CD}^{+}{ }^{+} \mathrm{CD} 56^{+} \mathrm{NKT}$ lymphocytes from liver biopsies of patients with an IFN $\lambda 4$ producing genotype ${ }^{39}$.

In conclusion, our study highlights a non-canonical effect of intracellularly retained IFN $\lambda 4$. Small amounts of IFN $\lambda 4$ are secreted, and these molecules are highly potent antiviral inducers of the JAK-STAT interferon signaling pathway. However, most of the IFN $\lambda 4$ is retained in the ER and causes ER stress. ER stress interferes with $\mathrm{HCV}$ antigen peptide loading and surface presentation by MHC-I complexes. As a consequence, $\mathrm{T}$ cell responses are attenuated, favoring viral escape from the cellular immune response that is known to be crucial for viral clearance.

\footnotetext{
Methods

Reagent or resource. Reagents used in this study are listed in Supplementary
} Table 1 .
Cell culture. A549 (ATCC Number: CCL-185), Huh7, and Huh7-LR ${ }^{16}$ cells were grown in low glucose (1 g/l) Dulbecco's modified Eagle (DMEM) medium (Gibco) supplemented with $10 \%$ fetal bovine serum (FBS) and $1 \%$ penicillin/streptomycin $(10,000 \mathrm{U} / \mathrm{ml})$ (ThermoFisher Scientific). Huh7.5 ${ }^{40}$ cells were grown in high glucose (4.5 g/l) Dulbecco's modified Eagle (DMEM) medium (Gibco) supplemented with $10 \%$ fetal bovine serum (FBS) and $1 \%$ penicillin/streptomycin. To generate IFNLR1-expressing Huh7.5.1 cells (Huh7.5.1-LR), Huh7.5.1 cells were transfected with pcDNA3.V5-IFNLR ${ }^{16}$ before selection with $1 \mathrm{mg} / \mathrm{ml}$ G418. Tetracyclineinducible HepG2 cell lines stably expressing IFN $\lambda 4$-GFP or IFN $\lambda 4$ p131-GFP were gifts from Dr. Ludmila Prokunina-Olsson ${ }^{41}$. Cells were cultured in a DMEM medium containing $1 \mathrm{mg} / \mathrm{ml} \mathrm{G} 418$ and $5 \mu \mathrm{g} / \mathrm{ml}$ blasticidin $\mathrm{S}$ hydrochloride. The

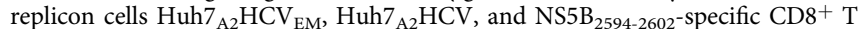
cell clone have previously been described ${ }^{26}$. Replicon cells were grown in high glucose ( $4.5 \mathrm{~g} / \mathrm{l})$ DMEM medium (Gibco) supplemented with $1 \%$ nonessential amino acids (Gibco), $1 \mathrm{mg} / \mathrm{ml} \mathrm{G} 418$, and $3 \mu \mathrm{g} / \mathrm{ml}$ blasticidin $S$ hydrochloride. The $\mathrm{CD}^{+} \mathrm{T}$ cell clone was cultivated in RPMI 1640 medium (Gibco) supplemented with 10\% human serum (PanBiotech), 1\% L-glutamine, and stimulated twice a week with $30 \mathrm{U} / \mathrm{ml}$ interleukine-2 (IL-2). CD8 ${ }^{+} \mathrm{T}$ cells were fed biweekly with irradiated peripheral blood mononuclear cells (PBMC) isolated from normal blood and stimulated with $40 \mu \mathrm{g} / \mathrm{ml}$ Phytohemagglutinin-M (PHA-M).

Protein expression and purification. Full-length open reading frames (ORF) for IFN $\alpha$, IFN $\lambda 1$, IFN $\lambda 2$, IFN $\lambda 3$, and IFN $\lambda 4$ were amplified using the primers shown in Supplementary Table 2 and cloned into the pcDNA4/To/myc-His B expression vector (ThermoFisher Scientific) or into the pCMV-mir-GFP expression vector (a gift from Jacek Krol). The IFN $\lambda 4$-TT expression plasmid was constructed by site-directed mutagenesis of " $\mathrm{C}_{65}$ " to " $\mathrm{AA}_{65-66}$ " in the IFN $\lambda 4$ sequence. Recombinant IFN protein were expressed in Huh7 cells by transient transfection with polyethylenimine (PEI) according to the manufacturer's instructions. Myc-His-tagged secreted IFN $\lambda 4$, IFN $\lambda 3$, and IFNa were purified from the culture supernatant $48 \mathrm{~h}$ post-transfection by $\mathrm{Ni}$ affinity chromatography using Ni Sepharose ${ }^{\mathrm{TM}} 6$ fast gravity-flow resin (GE Healthcare) according to the manufacturer's instructions. Specifically, Myc-Histagged proteins in supernatants were bound to the resin in buffer A (10 mM sodium phosphate, $10 \mathrm{mM}$ sodium hydrogen phosphate, $500 \mathrm{mM} \mathrm{NaCl}, 5 \mathrm{mM}$ imidazole, $\mathrm{pH}$ $7.8)$, and were eluted with buffer $\mathrm{B}(10 \mathrm{mM}$ sodium phosphate, $10 \mathrm{mM}$ sodium hydrogen phosphate, $500 \mathrm{mM} \mathrm{NaCl}, 500 \mathrm{mM}$ imidazole, $\mathrm{pH}$ 7.4) after two times washing with buffers containing $10 \mathrm{mM}$ and $20 \mathrm{mM}$ imidazole, respectively. Purified proteins were concentrated with Amicon Ultra-15 filters (Merck Millipore) and dialyzed against phosphate-buffered saline (PBS). Because of the low amounts of IFN $\lambda 4$ secreted from cells, 10 -fold more supernatant was used for IFN $\lambda 4$ than for IFN $\lambda 3$ purification. The purified IFN $\lambda 4$ and IFN $\lambda 3$ preparations were finally further concentrated to 0.3 and $0.5 \mathrm{ml}$, respectively. The identity and purity of the purified proteins were analyzed by western blotting using anti-IFN $\lambda 4$ (1:1000, Merck Millipore) and anti-IFN入3 (1:1000, Abcam) antibodies (Supplementary Fig. 3a-c). Because of the much larger starting volume and final concentration necessary for IFN $\lambda 4$ compared to IFN $\lambda 3$ purification, the IFN $\lambda 4$ preparation still contained some contaminating protein which we determined to be primarily carry over serum albumin that was present in the cell-culture supernatant used for protein purification (Supplementary Fig. 3a, b). Serum albumin however does not contribute to activation of the Jak-STAT interferon signaling pathway (Supplementary Fig. 3g). Because of the contaminating serum albumin, however, the IFN $\lambda 4$ concentration in the purified preparation could not be directly measured. Therefore, the IFN $\lambda 4$ concentration was determined by anti-Myc-specific (1:1000, Cell Signaling) western blotting using the purified IFN $\lambda 3$ as a reference (Supplementary Fig. 3e). The concentration of purified IFN $\lambda 3$ was determined independently with three different methods: (i) Absorbance at $280 \mathrm{~nm}$ (Nanodrop) using a protein molar extinction coefficient of 11,500 and a molecular weight of $26 \mathrm{KDa}$, (ii) Bio-Rad protein assay (Bio-Rad) at absorbance 595 nm, (iii) $12 \%$ SDS-PAGE followed by silver staining using bovine serum albumin (BSA) (SigmaAldrich) as a standard (i.e., 50, 100, 200, and $400 \mathrm{ng}$ ) (Supplementary Fig. $3 d$ ). Each assay yielded very similar IFN $\lambda 3$ concentrations and the one obtained 
a

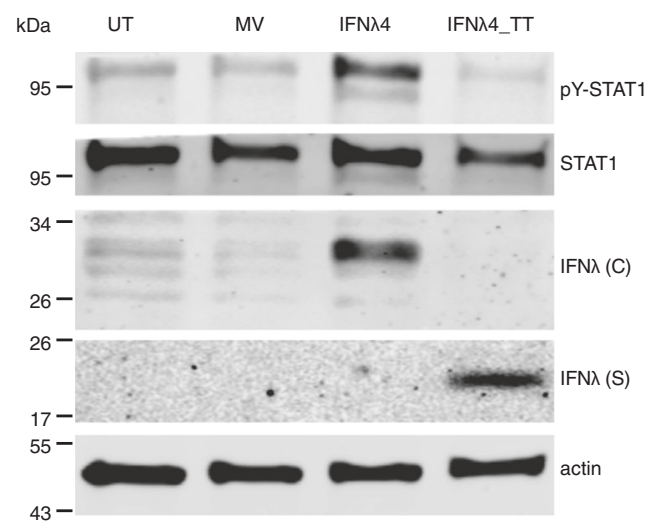

b

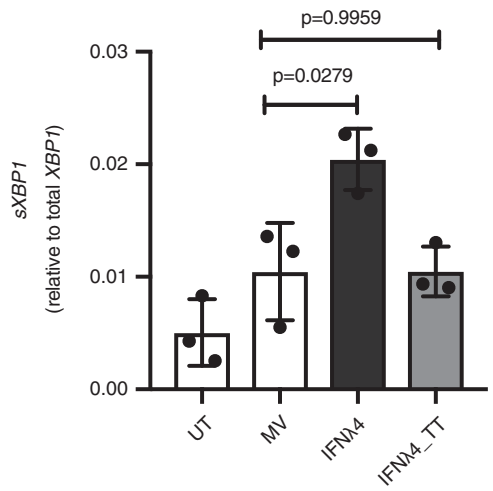

C
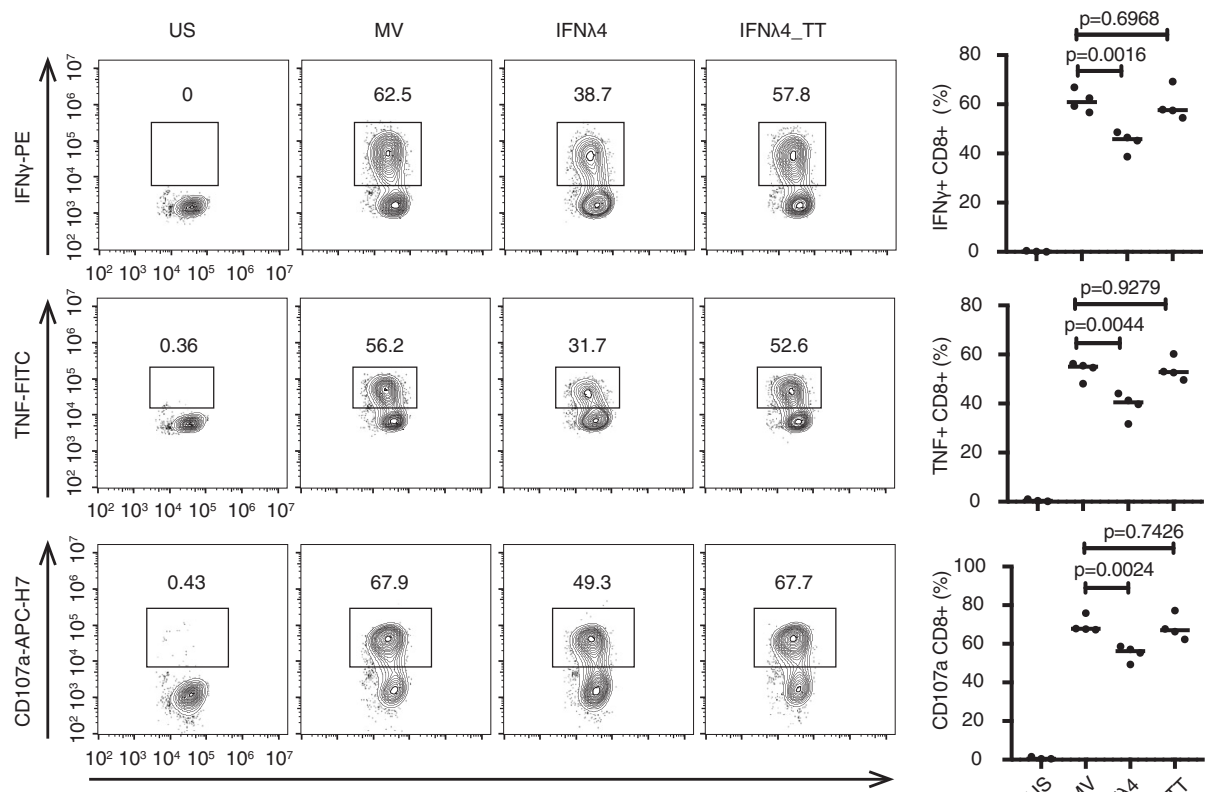

CD8-APC

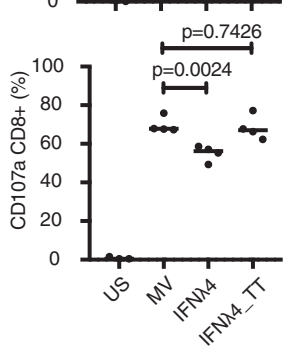

by silver staining was used for all subsequent experiments and quantification of purified IFN $\lambda 4$. The quantification of the purified IFN $\lambda 4$ and IFN $\lambda 3$ preparation was confirmed by silver staining after separation by $12 \%$ SDS-PAGE (Supplementary Fig. 3f). E. coli-derived IFN $\lambda 3$ and IFN $\lambda 4$ proteins harboring N-terminal $6 \times$ His tags were kindly provided as a gift by Prof. Rune Hartmann ${ }^{10}$. The Fiji distribution of Image $\int^{42}$ was used for protein quantification of silver staining and western blot images.
Kinetics of expression and secretion of IFN $\lambda$ s. IFN $\lambda 4$ or IFN $\lambda 3$ carrying $\mathrm{PcDNA} / \mathrm{To} / \mathrm{myc}$-His B plasmids were transiently transfected into Huh7 cells using PEI, in 5 wells of a 24-well plate, respectively. In the following 5 days, cells in one of the 5 wells were harvested every $24 \mathrm{~h}$ to monitor intracellular IFN $\lambda$ accumulation. Cells were lysed in the culture plates in $200 \mu$ Laemmli buffer containing $\beta$ mercaptoethanol (SigmaAldrich) and a protease inhibitor cocktail (PI, SigmaAldrich). In addition, supernatant (in total $250 \mu \mathrm{l}$ ) was collected and replaced with 
Fig. 7 IFN $\lambda$ 4-TT does not inhibit HCV peptide-specific CD8 $+\mathbf{T}$ cell activation. a Huh7 cells were transfected with expression vectors encoding IFN $\lambda 4$, IFN $\lambda 4$-TT or a mock vector (MV) or left untreated (UT). Cell lysates and cell-culture supernatants were collected $24 \mathrm{~h}$ later. Cell lysates were analyzed by western blotting for STAT1 activation (pY-STAT1, STAT1), as well as intracellular IFN $\lambda$ (IFN $\lambda(C)$ ) using an anti-Myc-tag antibody. IFN $\lambda$ proteins in the supernatants (IFN $\lambda(\mathrm{S})$ ) were also detected with an anti-Myc-tag antibody. Data are representative of $n=3$ independent experiments. $\mathbf{b} \mathrm{Huh}_{\mathrm{A} 2} \mathrm{HCV} \mathrm{V}_{\mathrm{EM}}$ cells were transfected with expression vectors for IFN $\lambda 4$ and IFN $\lambda 4$-TT or a mock vector (MV) or were left untreated (UT). Total RNA was harvested $48 \mathrm{~h}$ after transfection. Expression of the ER stress marker $S X B P 1$ was analyzed as described in Fig. 4d. Results are presented as mean \pm SEM of $n=3$ independent experiments. $p=0.0279, \mathrm{MV}$ vs IFN $\lambda 4 ; p=0.9959, \mathrm{MV}$ vs IFN $\lambda 4$ _TT, two-tailed unpaired $t$-test. $\mathbf{c}$ Huh7 ${ }_{\mathrm{A} 2} \mathrm{HCV}_{\mathrm{EM}}$ cells were transfected as described in (b) and were $48 \mathrm{~h}$ later cocultured with the $\mathrm{NS}^{2} \mathrm{~B}_{2594-2602}$-specific CD8 ${ }^{+} \mathrm{T}$ cell clone for $5 \mathrm{~h}$. Flow cytometry analysis was performed exactly as described in Fig. 6a. The right panel shows the results of mean \pm SEM from $n=4$ independent experiment. IFN $\gamma^{+} \mathrm{CD} 8^{+}: p=0.0016, M V$ vs IFN $\lambda 4, p=$

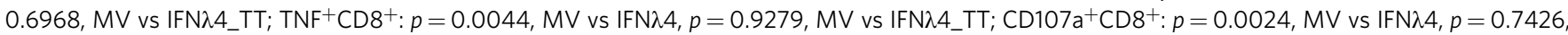
MV vs IFN $\lambda 4$ _ TT, all by two-tailed unpaired $t$-test. Source data are provided as a Source Data file.

fresh medium $(250 \mu \mathrm{l})$ every $24 \mathrm{~h}$ until cells were harvested. Untransfected cells were used as a negative control. Proteins in $25 \mu \mathrm{l}$ of each supernatant and $20 \mu \mathrm{l}$ of each cell lysate were resolved by $10 \%$ SDS-PAGE and transferred onto a nitrocellulose membrane (Waterman) by Trans-Blot Turbo Transfer System (Bio-Rad). Blotted proteins were detected with a monoclonal anti-Myc-tag antibody (1:1000, Cell Signaling) and visualized using a near-infrared-fluorescent dye (IRDye)-conjugated secondary anti-rabbit IgG (1:10,000, IRDye $800 \mathrm{CW}$, Licor). Images were captured on an Odyssey-CLx image system (Licor). To visualize IFN $\lambda 4$ in the supernatant, the same membranes were reblotted with a monoclonal anti-IFN $\lambda 4$ antibody (1:1000, Merck Millipore) and a secondary anti-mouse IgG (1:10,000, IRDye 680RD, Licor). Protein signal intensities were quantified from the western blot images using Fiji.

RNA extraction, reverse transcription, and quantitative real-time PCR. Total RNA was extracted from cells using the Trizol reagent (Ambion) according to the manufacturer's instructions. Total RNA was subjected to DNase I treatment using the DNA-freeTM DNA Removal Kit (Ambion) following the manufacturer's instructions. RNA concentrations were determined using a NanoDrop 2000 spectrophotometer (ThermoFisher Scientific). cDNA was synthesized from 200 to 400 ng of total RNA using MultiScribe Reverse Transcriptase (Applied Biosystems) and random hexamer primers in a $25 \mu \mathrm{l}$ reaction. Real-time quantitative PCR (RTqPCR) was performed with $10 \%$ of each RT-reaction using the FastStart Universal SYBR Green Master (Roche Diagnostics) on an ABI 7500 or 7500 Fast Real-Time PCR System (Applied Biosystems). Primers used for RT-qPCR are listed in Supplementary Table 3 . The amplification data were analyzed with the 7500 Software v2.0.6 (Applied Biosystems). Quantification of IFNL4 gene expression was performed using the TaqMan Universal Master Mix (ThermoFisher Scientific). For a non-discriminative quantification of IFNL4 transcripts, the TaqMan assay described in Amanzada et al. ${ }^{9}$ was used. Forward and reverse primers are complementary to sequences within exon 3 ( $5^{\prime}$-GAGGGATGTGGCGGCCTG-3') and exon $5\left(5^{\prime}\right.$ GACCACGCTGGCTTTGCG-3'), respectively, and a FAM-labeled minor groove binder (MGB) probe ( $5^{\prime}$-CCCGGAGAG CGGAC-3') was designed to span the exon 4-5 boundary to further enhance PCR specificity. Target gene expression levels were quantified based on standard curves comprise of serial dilutions of plasmids containing either the corresponding complete cDNA or PCR amplicon region and expressed as copy numbers per $40 \mathrm{ng}$ of total RNA. The lower limit of detection (LoD) for each RT-qPCR was set as the lowest detectable dilution of the corresponding standard curve. Alternatively, gene expression was expressed relative to that of the housekeeping gene GAPDH.

JAK-STAT activity assay and ISG induction analysis. For one-time point experiments, Huh7-LR cells were treated for $30 \mathrm{~m}$ or $6 \mathrm{~h}$ with either serial dilutions of purified IFN $\lambda 4$ and IFN $\lambda 3$ or specific amounts of IFN $\lambda 4$ and

IFN $\lambda 3$ supernatants. For kinetic assays, Huh7-LR cells were treated with undiluted IFN $\lambda 4$ supernatant and a 1:100 dilution of IFN $\lambda 3$ supernatant for $0.5,1,2,4,8,16$, $24 \mathrm{~h}$. For type I IFN inhibition with B18R, Huh7-LR cells were pre-incubated with B18R (R\&D Systems,125, 250, 500, $1000 \mathrm{ng} / \mathrm{ml}$ ) for $2 \mathrm{~h}$. After washing, cells were then incubated with recombinant IFNa (Roferon-A) $(250,500,1000 \mathrm{UI} / \mathrm{ml}$ ) or with specific amounts of IFN $\lambda 4$ and IFN $\lambda 3$ supernatants for $30 \mathrm{~m}$. Cells were lysed in Laemmli buffer and analyzed for total STAT1/2 protein, phospho-STAT1/2, and $\beta$-actin by western blotting. Antibodies were listed in the reagent table in Supplementary Table 1 . Western blots were performed as described above. STAT activation was quantified as the ratio of phospho-STAT intensity to total STAT intensity using the Fiji application. Total RNA was isolated from cells treated for 6 $\mathrm{h}$ for ISG expression analysis by RT-qPCR as described above.

IFN activity reporter assay. Huh7-LR cells were electroporated using Cytomix ${ }^{43,44}$ with $10 \mu \mathrm{g}$ of the interferon-stimulated response element (ISRE)-Mx1 firefly luciferase reporter construct (pGL3-Mx1P-FF-Luc, a gift from Rune Hartmann). $18 \mathrm{~h}$ after electroporation, the cell-culture medium was replaced with fresh medium containing serial dilutions of IFN $\lambda 4$ and IFN $\lambda 3$. Cells were lysed $6 \mathrm{~h}$ later in Passive Lysis Buffer (Promega) and firefly luciferase levels were measured using a multi-mode microplate reader (Centro XS3 LB960, Berthold Technologies)

Hepatitis C virus infection. Recombinant cell-culture-derived HCV (HCVcc) virus (strain JFH1/D183) ${ }^{45}$ was generated as previously described ${ }^{46}$. Huh7.5.1-LR cells were infected with HCVcc for $6 \mathrm{~h}(\mathrm{MOI}=1)$ before adding IFN $\lambda 4(1$ and 10 $\mathrm{ng} / \mathrm{ml})$ or IFN $\lambda 3(1,10$, and $50 \mathrm{ng} / \mathrm{ml})$. Total cellular RNA was extracted $48 \mathrm{~h}$ postinfection and intracellular HCV RNA and ISG mRNA were analyzed by quantitative RT-qPCR.

Protein deglycosylation. Secreted and purified IFN $\lambda 4$ was treated with PNGase F, $O$-glycosidase, $\beta$ - $N$-acetyl glucosaminidase, $\beta 1-4$ galactosidase or $\alpha 2-3,6,8$ neuraminidase individually, or with a protein deglycosylation mix (Mix-I, an enzyme mix of PNGase F, $O$-glycosidase, $\beta$ - $N$-acetyl glucosaminidase, $\beta 1-4$ galactosidase or $\alpha 2-3,6,8$ neuraminidase) or with an enzyme mix of $\beta$ - $N$-acetylglucosminidase, $\beta$ 1-4 galactosidase, neuraminidase (Mix-II) for $1 \mathrm{~h}$ at $37^{\circ} \mathrm{C}$. Cell lysates of IFN $\lambda 4-$ expressed Huh7 cells were produced in ice-cold sucrose homogenization medium (SHM) (sucrose $0.25 \mathrm{M}$, HEPES $10 \mathrm{mM}, \mathrm{pH}$ 7.4) containing a PI cocktail. Cell homogenates were then treated with PNGase $\mathrm{F}$ at $37^{\circ} \mathrm{C}$ for $1 \mathrm{~h}$. The corresponding molecular weights of the treated and control mock-treated IFN $\lambda 4$ were visualized by western blotting with a monoclonal anti-IFN $\lambda 4$ antibody (1:1000, Merck Millipore) as described above.

Immunofluorescence microscopy. Huh7 cells were cultured in 4-well chamber slides (Nunc Lab-Tek, SigmaAldrich). $24 \mathrm{~h}$ after transfection with pcDNA4/To/ $m y c$-His B-IFNג4 plasmid or with pcDNA4/To/myc-His B vector, using PEI, cells were fixed with $4 \%$ paraformaldehyde and then permeabilized with $0.1 \%$ Triton X-100 in PBS containing 2\% BSA. Fixed and permeabilized cells were incubated with anti-IFN $\lambda 4$ (Merck Millipore, $5 \mu \mathrm{g} / \mathrm{ml}$ ) and anti-Giantin antibodies (Abcam,1 $\mu \mathrm{g} / \mathrm{ml}$ ) in PBS containing $2 \%$ BSA for $1 \mathrm{~h}$ at $37^{\circ} \mathrm{C}$. After three times washing with PBS, the corresponding secondary antibodies (goat anti-rabbit 647, 1:1000, and goat anti-mouse $488,1: 400$ ) were added under the same conditions as the primary antibodies. Excess antibodies were removed by three times washing with PBS. Endoplasmic reticulum (ER) staining was performed with the Cytopainter ER staining Kit-Red Fluorescence (Abcam) for $30 \mathrm{~m}$ at $37^{\circ} \mathrm{C}$. Slides were mounted with Roti-mount FlourCare DAPI (Carl Roth). Confocal microscopy was performed with a Zeiss LSM 710 confocal microscope and images were acquired with the ZEN 2010 software (Carl Zeiss). The colocalization coefficient (Pearson's coefficient) was quantified in ImageJ using the plug-in, JACoP (Just Another Colocalization Plug-in $)^{47}$

Subcellular fractionation. The subcellular localization of IFN $\lambda 4$ and IFN $\lambda 3$ was determined in Huh7 cells $24 \mathrm{~h}$ after transfection with pcDNA4/To/myc-His B-IFN $\lambda 4$ or with pcDNA4/To/myc-His B-IFN $\lambda 3$, respectively, using PEI. $6 \times 10^{7}$ cells were resuspended in $2 \mathrm{ml}$ ice-cold SHM containing a PI cocktail and homogenized in a Dounce homogenizer using a tight pestle. The cell homogenate (HM) was subjected to a 2-step fractionation procedure. First, differential centrifugation was used to sediment crude organelles components such as crude mitochondria (cMito), crude plasma membrane (cPM), microsome (MS), and cytosol (Cyto) fractions $\mathrm{s}^{48,49}$. Second, the sedimented cMito, cPM, and MS fractions were resuspended in $0.5 \mathrm{ml}$ Tris/EDTA buffer (TE) (10 mM TrisCl, $0.1 \mathrm{mM}$ EDTA, PH 6.0) and subjected to density gradient centrifugation. Discontinuous iodixanol (OptiPrep, 60\% wt/vol) gradients $(5,10,15,20,30,32.5,35$, and $40 \%$ from top to bottom) were prepared in a 5-ml ultra-clear SW55Ti centrifugation tube (Beckman Coulter $)^{50}$. The resuspended cMito, cPM, and MS fractions were loaded on top of the iodixanol gradients, and centrifuged in an SW55Ti rotor at 200,000 $\times g$ for $2 \mathrm{~h}$. The centrifugation resulted in three visible bands. Fractions containing individual bands were collected and filled up to $12 \mathrm{ml}$ with SHM/PI buffer, and pelleted by centrifugation in an SW32Ti rotor at $100,000 \times g$ for $40 \mathrm{~m}$. Pellets were resuspended in $250 \mu \mathrm{l}$ SHM/PI. IFN $\lambda 4$ and IFN $\lambda 3$ in different compartments were quantified by Myc-tag-specific western blot analysis of $2 \mu \mathrm{l}$ of each fraction (HM, PM, ER, ER-PM, Cyto) as described above. PM and ER markers were detected with 
anti-E-cadherin (1:1000, Cell Signaling) and anti-calnexin (1:500, Santa-Cruz) antibodies, respectively. IFN $\lambda 4$ and IFN $\lambda 3$ protein concentrations in each fraction were quantified using purified IFN $\lambda 3(25,50,100 \mathrm{ng})$ as a standard. STAT1/2 activation by the IFN $\lambda 4$ and IFN $\lambda 3$ containing fractions was analyzed as described above.

ER stress analysis. For western blot detection, Huh7 cells were transfected with IFN-expression plasmids using PEI as described above. Cells were harvested either at $24 \mathrm{~h}$ or for kinetic studies at $8,12,24$, and $48 \mathrm{~h}$ after transfection and/or drug treatment and subjected to western blot analysis for the detection of IRE1 1 , phosphor- IRE1 $\alpha$, PERK, phosphor-PERK, Bip, cleaved ATF6 (cATF6), ATF4, phospho-eIF2 $\alpha$, eIF2 $\alpha$, and Myc-tagged IFNs. 4-15\% Mini-PROTEAN TGX StainFree Precast Gels (Bio-Rad) and Trans-Blot Turbo Mini $0.2 \mu \mathrm{m}$ Nitrocellulose Transfer Packs (Bio-Rad) were used for SDS-PAGE separation and Western blotting. For gene expression analysis, Huh7 cells were transfected with IFNexpression plasmids or incubated with IFN supernatants from transfected Huh7 cells at the indicated time points. Cellular RNA was extracted and used for RTqPCR as described above. The expression level of spliced $s X B P 1$ mRNA was calculated relative to the expression level of total XBP1 mRNA. CHOP mRNA expression was calculated relative to that of the housekeeping gene GAPDH. Huh-7 cells treated with $2 \mu \mathrm{M}$ Thapsigargin (SigmaAldrich) for 4,8 , and $12 \mathrm{~h}$ served as a positive control for ER stress induction. HepG2 cell lines stably expressing IFN $\lambda 4$ GFP or IFN $\lambda 4$ p131-GFP were cultured in the presence of increasing amounts of doxycycline $(0,0.01,0.02,0.05,0.1,0.2,0.5 \mu \mathrm{g} / \mathrm{ml})$. After $24 \mathrm{~h}$ of doxycycline induction, IFN $\lambda 4$-GFP and IFN $\lambda 4$ p131-GFP expression in the cells and supernatant was quantified by western blotting using an anti-IFN $\lambda 4$ antibody $(1: 1000$, Merck Millipore) as described above.

\section{Organoid culture and hepatocyte differentiation. Organoid cultures (Supple-} mentary Table 4) were generated from liver-derived needle biopsies as previously described $^{24,51}$. Briefly, liver-derived biopsies were digested with $2.5 \mathrm{mg} / \mathrm{ml}$ collagenase IV (Sigma), $0.1 \mathrm{mg} / \mathrm{ml}$ DNase (Sigma), and the released cells were seeded into droplets of reduced growth factor Basement Membrane Extract, type 2 (BME2) (Amsbio). After BME2 polymerization, expansion medium ${ }^{51}$ was added to the cells. Liver organoids were passaged after dissociation with $0.25 \%$ TrypsinEDTA (Gibco). For hepatocyte differentiation, liver organoids were kept for at least 5 days in an expansion medium supplemented with BMP7 $(25 \mathrm{ng} / \mathrm{ml})$ before switching to differentiation medium ${ }^{51}$ for a period of $11-15$ days with regular medium changes. Organoid lines are available upon request.

DNA extraction and IFN $\lambda \mathbf{4}$ genotyping. Total DNA was isolated from organoids using DNeasy Blood \& Tissue Kit (Qiagen) according to the manufacturer's instructions. IFNL4 genotyping was performed exactly as described previously ${ }^{15}$. A fragment of 850 base pair covering rs368234815 and rs117648444 was amplified with the Expand High Fidelity PCR System (Roche) using forward 5'-

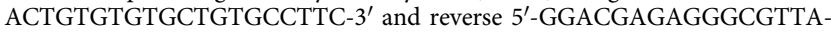
GAG- $3^{\prime}$ primers. The PCR product was purified using the NucleoSpin Gel and PCR clean-up kit (Macherey-Nagel AG) according to the manufacturer's instructions before sequencing (Microsynth AG).

Sendai virus infection in cell lines and in liver-derived organoid. A549 cells were infected with Sendai virus (H4 strain) (a gift from Prof Dominique Garcin of the University of Genève, Genève, Switzerland $)^{52}$ at $\mathrm{MOI}=5$. Cells were harvested at 3,6 , $9,12,24 \mathrm{~h}$ post-infection. Total cellular RNA was extracted with Trizol reagent and IFNL4 mRNA expression was quantified by RT-PCR as described above. Expression analysis of endogenously induced IFN $\lambda 4$ and IFN $\lambda 3$ was analyzed by Western blotting as described above using cell lysates harvested 6 and $12 \mathrm{~h}$ post-infection.

Organoids were derived from liver biopsies of patients enrolled in this study. The study was carried out in accordance with The Code of Ethics of the World Medical Association (Declaration of Helsinki) and was approved by the Ethics Committee of North Western Switzerland (Authorization number EKNZ 2014-362). Written informed consent was obtained from all patients enrolled in this study. Organoids that underwent hepatocyte differentiation were removed from BME2 using cold PBS and washed 3 times with PBS. Suspended organoids were then infected with Sendai virus (H4 strain) at an MOI $=10$ for $1 \mathrm{~h}$ before seeding them back into BME2 as described above. For RNA extraction, organoids were released from BME2 by incubating with $0.25 \%$ Trypsin for $5 \mathrm{~min}$ at $37^{\circ} \mathrm{C}$ followed by Trypsin inactivation with DMEM/10\%FBS, and total RNA was extracted using the ZR-Duet DNA/RNA miniprep kit (Zymo Research) according to the manufacturer's instructions. Sendai virus RNA and mRNAs of IFNs and ISGs were quantified by RT-qPCR as described above using the genes-specific primers shown in Supplementary Table 3. For the detection of endogenously produced IFN $\lambda 4$ protein, organoids were released from BME2 by incubation in Cell Recovery Solution (Corning) and subsequent processing using the Mem-PER Membrane protein Extraction Kit (ThermoFisher Scientific) according to the manufacturer's instructions. The membrane fractions were used for IFN $\lambda 4$-specific western blotting. The blots were first treated with Super Signal Western blot enhancer (ThermoFisher Scientific) for $10 \mathrm{~m}$ according to the manufacturer's instruction. After 5-times washing with double-distilled water $\left(\mathrm{ddH}_{2} \mathrm{O}\right)$, the blots were incubated with IFN $\lambda 4$-specific antibody (1:1000, Abcam) and an HRPconjugated goat anti-rabbit secondary antibody (1:5000, ThermoFisher Scientific). The image was captured on Gel Doc XR+ System (Bio-Rad).

RNA sequencing and analysis. RNA was extracted from six organoid lines (Supplementary Table 4) pre- and $12 \mathrm{~h}$-post mock-or SeV infection as described above. 100 ng total RNA of each sample was used for RNA sequencing library preparation with NEBNext Ultra II Directional RNA Library Prep Kit for Illumina with sample purification beads (New England Biolabs) according to manufacturer's specifications. SR150 sequencing was performed on an Illumina NextSeq 550 System at the Institute of Medical Genetics and Pathology (University Hospital Basel) according to the manufacturer's guidelines. Primary data analysis was performed with the Illumina Real-Time Analysis software (RTA version 1.18.66.3). Sequence reads were aligned by STAR ${ }^{53}$ using the two-pass approach to the human reference genome GRCh37. Gene quantification was performed using RSEM, a software package for estimating gene and isoform expression levels from RNAseq data ${ }^{54}$. Gene expression analysis was performed using the edgeR R package ${ }^{55}$ in RStudio v3.6. Specifically, genes with counts-per-million $(\mathrm{cpm})<1$ in $\geq 3$ samples were removed. Normalization was performed using the "TMM" (weighted trimmed mean) method. cpm values were log2-transformed prior to plotting by multidimensional scaling (MDS) using the top 500 pairwise variable genes. Differential gene expression analysis between $\mathrm{SeV}$-infected and uninfected samples was performed using the quasi-likelihood $F$-test. Uninfected organoids at time points 0 and $12 \mathrm{~h}$ were treated as biological replicates. All tests were performed treating samples from the same organoids as paired samples. Genes with FDR $\leq 0.05$ were considered differentially expressed. Representative analysis of Gene Ontology (GO) term was performed with the clusterProfiler package ${ }^{56}$ in $d G$ and $T T$ organoids, respectively. Gene Set Enrichment analysis was conducted to compare differences between SeV-infected organoids of $d G$ and $T T$ genotypes in pathway levels, with the R-package "fgsea", version 1.14.0 $0^{57}$, and Gene Ontology-Biological Process (GO-BP) from MSigDB, version $7.2^{58}$. For fgsea, parameters nperm $=10,000$ and minSize $=5$ were set. As separating score, sign $(\log \mathrm{FC}) *$ F-statistic was used, computed from the edgeR differential comparison of (dG.S-dG.PM) vs (TT.S-TT.PM). Leading genes of the selected pathway "GO_RESPONSE_TO_ENDOPLASMIC_RETICULUM_STRESS" were plotted as the log2 fold-change in expression levels induced by $\mathrm{SeV}$ infection in organoids of the $T T$ genotype against the $d G$ genotype.

HCV replication and HLA-A2 quantification of $\mathbf{H C V}$ replicon cells. $0.5 \times 10^{5}$ $\mathrm{Huh}_{\mathrm{A} 2} \mathrm{HCV}_{\mathrm{EM}}$ replicon cells/well were seeded in a 24-well plate one day before PEI transfection with a mock vector or expression plasmids for IFN $\lambda 1$, IFN $\lambda 3$, IFN $\lambda 4$, and IFN $\lambda 4$-TT or were incubated with IFN $\lambda 3$ and IFN $\lambda 4$ containing supernatants. Forty-eight hours post-transfection or incubation, HCV replication levels were determined by using the Steady-Glo Luciferase Assay System (Promega) according to the manufacturer's instructions. For surface HLA-A2 staining, cells were harvested $48 \mathrm{~h}$ post-transfection and stained with anti-human HLA-A2 BV650 antibody (1:50). Data was acquired using a CytoFLEX (Beckman) flow cytometer and analyzed with Flowjo 10.4 (FlowJo, LLC).

HCV replicon cells and $\mathbf{C D 8}{ }^{+} \mathbf{T}$ cells coculture assay. $\mathrm{Huh} 7_{\mathrm{A} 2} \mathrm{HCV}_{\mathrm{EM}}$ replicon cells were transfected or incubated with supernatant of IFN $\lambda 3$ and IFN $\lambda 4$ as described above. Forty-eight hours post-transfection, replicon cells were cocultured

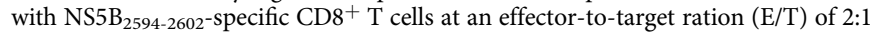
in a total of $500 \mu \mathrm{l}$ medium in the presence of brefeldin A. After $5 \mathrm{~h}$ of coculture, cells were harvested. Live/dead cell staining was perform using a Zombi aqua fixable viability kit (Biolegend). After washing with $2 \%$ BSA, cells were stained with anti-CD8-APC (1:50) and anti-CD107a-APC-H7 (1:25) diluted in 2\% BSA for $30 \mathrm{~m}$ at $4{ }^{\circ} \mathrm{C}$. Thereafter, cells were fixed (IC fixation buffer, eBioscience) and permeabilized (permeabilization buffer, eBioscience) according to the manufacturer's instruction. Intracellular IFN $\gamma$ and TNF staining was performed with anti-IFN $\gamma$-PE (1:20) and anti-TNF $\alpha$-FITC (1:2) diluted in permeabilization buffer for $30 \mathrm{~m}$ at $4{ }^{\circ} \mathrm{C}$. Huh7 ${ }_{\mathrm{A} 2} \mathrm{HCV}_{\mathrm{EM}}$ replicon cells were treated with $2 \mu \mathrm{M}$ Thapsigargin for $24 \mathrm{~h}$ before coculturing with $\mathrm{CD} 8^{+} \mathrm{T}$ cells as described above. Data was acquired using a CytoFLEX (Beckman) flow cytometer and analyzed with Flowjo 10.4. The cell gating strategy is shown in Supplementary Fig. 12. For T cell coculturing assay with the mismatched replicon cells, $\mathrm{Huh} 7_{\mathrm{A} 2} \mathrm{HCV}$ cells were transfected with the IFN-expression plasmids as described above. $48 \mathrm{~h}$-posttransfection, the $\mathrm{NS} 5 \mathrm{~B}_{2594-2602}$-peptide Alydvvtkl $(10 \mu \mathrm{g} / \mathrm{ml})$ was added to the cell culture medium for $1 \mathrm{~h}$ at $37^{\circ} \mathrm{C}$. Then, the cells were washed twice with a fresh medium before coculturing with the $\mathrm{CD} 8^{+} \mathrm{T}$ cells in the presence of brefeldin $\mathrm{A}$ and subsequent flow cytometry analysis of the $\mathrm{CD} 8^{+} \mathrm{T}$ cells as described above.

Statistical analysis. Data are presented as mean value \pm SEM. Data were analyzed with Prism8 (GraphPad Software Inc, La Jolla, USA) using a student's two-tailed $t$ test for unpaired data. In all analyses, a two-tailed $p<0.05(95 \%$ confidence interval) was considered statistically significant. Western blot, gel staining, immunofluorescence, and flow cytometry data are representative of three or more independent experiments. 
Reporting summary. Further information on research design is available in the Nature Research Reporting Summary linked to this article.

\section{Data availability}

All data that support the findings of this study are available within the manuscript and the supplementary information files or from the corresponding author upon reasonable request. The RNA-Seq data reported here have been deposited in the European GenomePhenome Archive under primary accession number: EGAS00001005396. Source data are provided with this paper.

\section{Code availability}

The computational code used for the RNAseq analysis is provided as Supplementary Methods in the Supplementary Information file.

Received: 8 July 2020; Accepted: 26 July 2021; Published online: 12 August 2021

\section{References}

1. Ye, L., Schnepf, D. \& Staeheli, P. Interferon-lambda orchestrates innate and adaptive mucosal immune responses. Nat. Rev. Immunol. 19, 614-625 (2019).

2. Ge, D. et al. Genetic variation in IL28B predicts hepatitis C treatment-induced viral clearance. Nature 461, 399-401 (2009).

3. Heim, M. H., Bochud, P. Y. \& George, J. Host - hepatitis C viral interactions: the role of genetics. J. Hepatol. 65, S22-S32 (2016).

4. Rauch, A. et al. Genetic variation in IL28B is associated with chronic hepatitis $\mathrm{C}$ and treatment failure: a genome-wide association study. Gastroenterology 138, 1338-1345 (2010). 1345.e1331-1337.

5. Suppiah, V. et al. IL28B is associated with response to chronic hepatitis C interferon-alpha and ribavirin therapy. Nat. Genet. 41, 1100-1104 (2009).

6. Tanaka, Y. et al. Genome-wide association of IL28B with response to pegylated interferon-alpha and ribavirin therapy for chronic hepatitis C. Nat. Genet. 41, 1105-1109 (2009).

7. Thomas, D. L. et al. Genetic variation in IL28B and spontaneous clearance of hepatitis C virus. Nature 461, 798-801 (2009).

8. Prokunina-Olsson, L. et al. A variant upstream of IFNL3 (IL28B) creating a new interferon gene IFNL4 is associated with impaired clearance of hepatitis C virus. Nat. Genet. 45, 164-171 (2013).

9. Amanzada, A., Kopp, W., Spengler, U., Ramadori, G. \& Mihm, S. Interferonlambda4 (IFNL4) transcript expression in human liver tissue samples. PLoS ONE 8, e84026 (2013).

10. Hamming, O. J. et al. Interferon lambda 4 signals via the IFNlambda receptor to regulate antiviral activity against $\mathrm{HCV}$ and coronaviruses. $E M B O$ J. 32, 3055-3065 (2013).

11. Hong, M. et al. Interferon lambda 4 expression is suppressed by the host during viral infection. J. Exp. Med. 213, 2539-2552 (2016).

12. Obajemu, A. A. et al. IFN-lambda4 attenuates antiviral responses by enhancing negative regulation of IFN signaling. J. Immunol. 199, 3808-3820 (2017).

13. Zhou, H. et al. The IFNL4 gene is a non-canonical interferon gene with a unique but evolutionarily conserved regulation. J. Virol. 94, 1-14 (2019).

14. Lu, Y. F., Goldstein, D. B., Urban, T. J. \& Bradrick, S. S. Interferon-lambda4 is a cell-autonomous type III interferon associated with pre-treatment hepatitis C virus burden. Virology 476, 334-340 (2015).

15. Terczynska-Dyla, E. et al. Reduced IFNlambda4 activity is associated with improved HCV clearance and reduced expression of interferon-stimulated genes. Nat. Commun. 5, 5699 (2014).

16. Duong, F. H. et al. IFN-lambda receptor 1 expression is induced in chronic hepatitis $\mathrm{C}$ and correlates with the IFN-lambda3 genotype and with nonresponsiveness to IFN-alpha therapies. J. Exp. Med. 211, 857-868 (2014).

17. Colamonici, O. R., Domanski, P., Sweitzer, S. M., Larner, A. \& Buller, R. M. Vaccinia virus B18R gene encodes a type I interferon-binding protein that blocks interferon alpha transmembrane signaling. J. Biol. Chem. 270, 15974-15978 (1995).

18. Alcami, A., Symons, J. A. \& Smith, G. L. The vaccinia virus soluble alpha/beta interferon (IFN) receptor binds to the cell surface and protects cells from the antiviral effects of IFN. J. Virol. 74, 11230-11239 (2000).

19. Waibler, Z. et al. Vaccinia virus-mediated inhibition of type I interferon responses is a multifactorial process involving the soluble type I interferon receptor B18 and intracellular components. J. Virol. 83, 1563-1571 (2009).

20. Kotenko, S. V. et al. IFN-lambdas mediate antiviral protection through a distinct class II cytokine receptor complex. Nat. Immunol. 4, 69-77 (2003).

21. Hetz, C. The unfolded protein response: controlling cell fate decisions under ER stress and beyond. Nat. Rev. Mol. Cell Biol. 13, 89-102 (2012).
22. Walter, P. \& Ron, D. The unfolded protein response: from stress pathway to homeostatic regulation. Science 334, 1081-1086 (2011).

23. Huch, M. et al. In vitro expansion of single Lgr5+ liver stem cells induced by Wnt-driven regeneration. Nature 494, 247-250 (2013).

24. Nuciforo, S. et al. Organoid models of human liver cancers derived from tumor needle biopsies. Cell Rep. 24, 1363-1376 (2018).

25. Blum, J. S., Wearsch, P. A. \& Cresswell, P. Pathways of antigen processing. Annu. Rev. Immunol. 31, 443-473 (2013).

26. Jo, J. et al. Analysis of CD8+ T-cell-mediated inhibition of hepatitis C virus replication using a novel immunological model. Gastroenterology 136, 1391-1401 (2009).

27. Chinnaswamy, S. et al. A single nucleotide polymorphism associated with hepatitis $\mathrm{C}$ virus infections located in the distal region of the IL28B promoter influences NF-kappaB-mediated gene transcription. PLoS ONE 8, e75495 (2013).

28. McFarland, A. P. et al. The favorable IFNL3 genotype escapes mRNA decay mediated by AU-rich elements and hepatitis $\mathrm{C}$ virus-induced microRNAs. Nat. Immunol. 15, 72-79 (2014).

29. di Iulio, J. et al. Estimating the net contribution of interleukin-28B variation to spontaneous hepatitis C virus clearance. Hepatology 53, 1446-1454 (2011).

30. Lu, Y. F. et al. IFNL3 mRNA structure is remodeled by a functional noncoding polymorphism associated with hepatitis $\mathrm{C}$ virus clearance. Sci. Rep. $\mathbf{5}$, 16037 (2015).

31. Sugiyama, M., Tanaka, Y., Wakita, T., Nakanishi, M. \& Mizokami, M. Genetic variation of the IL-28B promoter affecting gene expression. PLOS ONE 6, e26620 (2011)

32. Wack, A., Terczynska-Dyla, E. \& Hartmann, R. Guarding the frontiers: the biology of type III interferons. Nat. Immunol. 16, 802-809 (2015).

33. Van den Steen, P., Rudd, P. M., Dwek, R. A., Van Damme, J. \& Opdenakker G. Cytokine and protease glycosylation as a regulatory mechanism in inflammation and autoimmunity. Adv. Exp. Med. Biol. 435, 133-143 (1998).

34. Sato, Y. et al. An N-glycosylation site on the beta-propeller domain of the integrin alpha5 subunit plays key roles in both its function and site-specific modification by beta1,4-N-acetylglucosaminyltransferase III. J. Biol. Chem. 284, 11873-11881 (2009)

35. Partridge, E. A. et al. Regulation of cytokine receptors by Golgi N-glycan processing and endocytosis. Science 306, 120-124 (2004).

36. Hebert, D. N., Lamriben, L., Powers, E. T. \& Kelly, J. W. The intrinsic and extrinsic effects of N-linked glycans on glycoproteostasis. Nat. Chem. Biol. 10, 902-910 (2014).

37. Tannous, A., Pisoni, G. B., Hebert, D. N. \& Molinari, M. N-linked sugarregulated protein folding and quality control in the ER. Semin. Cell Dev. Biol. 41, 79-89 (2015).

38. Eslam, M. et al. IFN-lambda3, not IFN-lambda4, likely mediates IFNL3IFNL4 haplotype-dependent hepatic inflammation and fibrosis. Nat. Genet. 49, 795-800 (2017).

39. Jouvin-Marche, E. et al. Lymphocytes degranulation in liver in hepatitis C virus carriers is associated with IFNL4 polymorphisms and ALT levels. J. Infect. Dis. 209, 1907-1915 (2014).

40. Blight, K. J., McKeating, J. A. \& Rice, C. M. Highly permissive cell lines for subgenomic and genomic hepatitis C virus RNA replication. J. Virol. 76, 13001-13014 (2002).

41. Onabajo, O. O. et al. Expression of interferon lambda 4 is associated with reduced proliferation and increased cell death in human hepatic cells. $J$. Interferon Cytokine Res. 35, 888-900 (2015).

42. Schindelin, J. et al. Fiji: an open-source platform for biological-image analysis. Nat. Methods 9, 676-682 (2012).

43. van den Hoff, M. J., Moorman, A. F. \& Lamers, W. H. Electroporation in 'intracellular' buffer increases cell survival. Nucleic Acids Res. 20, 2902 (1992).

44. Koutsoudakis, G. et al. Cell culture replication of a genotype $1 \mathrm{~b}$ hepatitis $\mathrm{C}$ virus isolate cloned from a patient who underwent liver transplantation. PLoS ONE 6, e23587 (2011).

45. Zhong, J. et al. Persistent hepatitis $C$ virus infection in vitro: coevolution of virus and host. J. Virol. 80, 11082-11093 (2006).

46. Takahashi, K. et al. Plasmacytoid dendritic cells sense hepatitis C virusinfected cells, produce interferon, and inhibit infection. Proc. Natl Acad. Sci. USA 107, 7431-7436 (2010).

47. Bolte, S. \& Cordelieres, F. P. A guided tour into subcellular colocalization analysis in light microscopy. J. Microsc. 224, 213-232 (2006).

48. Suski, J. M. et al. Isolation of plasma membrane-associated membranes from rat liver. Nat. Protoc. 9, 312-322 (2014)

49. Williamson, C. D., Wong, D. S., Bozidis, P., Zhang, A. \& Colberg-Poley, A. M. Isolation of endoplasmic reticulum, mitochondria, and mitochondriaassociated membrane and detergent resistant membrane fractions from transfected cells and from human cytomegalovirus-infected primary fibroblasts. Curr. Protoc. Cell Biol. 68, 27 21-23 2733 (2015).

50. Ding, W. et al. Endoplasmic reticulum and cis-Golgi localization of human T-lymphotropic virus type $1 \mathrm{p} 12(\mathrm{I})$ : association with calreticulin and calnexin. J. Virol. 75, 7672-7682 (2001) 
51. Huch, M. et al. Long-term culture of genome-stable bipotent stem cells from adult human liver. Cell 160, 299-312 (2015).

52. Strahle, L., Garcin, D. \& Kolakofsky, D. Sendai virus defective-interfering genomes and the activation of interferon-beta. Virology 351, 101-111 (2006).

53. Dobin, A. et al. STAR: ultrafast universal RNA-seq aligner. Bioinformatics 29, 15-21 (2013).

54. Li, B. \& Dewey, C. N. RSEM: accurate transcript quantification from RNA-Seq data with or without a reference genome. BMC Bioinformatics 12, 323 (2011).

55. Chen, Y., Lun, A. T. \& Smyth, G. K. From reads to genes to pathways: differential expression analysis of RNA-Seq experiments using Rsubread and the edgeR quasi-likelihood pipeline. F1000Res 5, 1438 (2016).

56. Yu, G., Wang, L. G., Han, Y. \& He, Q. Y. clusterProfiler: an R package for comparing biological themes among gene clusters. OMICS 16, 284-287 (2012).

57. Korotkevich, G. et al. Fast gene set enrichment analysis. Preprint at bioRxiv https://doi.org/10.1101/060012 (2021).

58. Subramanian, A. et al. Gene set enrichment analysis: a knowledge-based approach for interpreting genome-wide expression profiles. Proc. Natl Acad. Sci. USA 102, 15545-15550 (2005).

\section{Acknowledgements}

We thank Hans Henrik Gad and Rune Hartmann for providing recombinant human IFN $\lambda$ 4, Dominique Garcin for providing Sendai virus, and Ludmila Prokunina-Olsson for providing tetracycline-inducible HepG2 cell lines. This work was supported by Swiss National Science Foundation grants 310030B_185371 and 310030_166202 to M.H.H., by Deutsche Forschungsgemeinschaft grant TRR179, TP17 to V.L., and grant TR179, TP 1 to R.T.

\section{Author contributions}

Q.C. designed and performed experiments, analyzed RNAseq data, wrote the manuscript. M.C.-L. designed and performed experiments of IFN $\lambda 4$ expression, secretion, and JAKSTAT activation. A.S. designed and performed experiments of Sendai virus infection in liver-derived organoids. R.D.T. performed protein purification. I.F. and S.N. established liver-derived organoids. Designed and performed experiments of Sendai virus infection in liver-derived organoids. M.H., R.T., N.H., and V.L. provided HCV sub-genomic replicon cells and $\mathrm{CD}^{+} \mathrm{T}$ cell clones. C.K.Y.N. and G.R. analyzed RNAseq data. S.W. and M.H.H., designed and supervised the project and wrote the manuscript. M.H.H. obtained funding.

\section{Competing interests}

The authors declare no competing interests.

\section{Additional information}

Supplementary information The online version contains supplementary material available at https://doi.org/10.1038/s41467-021-25218-x.

Correspondence and requests for materials should be addressed to M.H.H.

Peer review information Nature Communications thanks Srikanta Dash, Sergei Kotenko and the other, anonymous, reviewer(s) for their contribution to the peer review of this work. Peer reviewer reports are available.

Reprints and permission information is available at http://www.nature.com/reprints

Publisher's note Springer Nature remains neutral with regard to jurisdictional claims in published maps and institutional affiliations.

Open Access This article is licensed under a Creative Commons Attribution 4.0 International License, which permits use, sharing, BY Attribution 4.0 International License, which permits use, sharing
adaptation, distribution and reproduction in any medium or format, as long as you give appropriate credit to the original author(s) and the source, provide a link to the Creative Commons license, and indicate if changes were made. The images or other third party material in this article are included in the article's Creative Commons license, unless indicated otherwise in a credit line to the material. If material is not included in the article's Creative Commons license and your intended use is not permitted by statutory regulation or exceeds the permitted use, you will need to obtain permission directly from the copyright holder. To view a copy of this license, visit http://creativecommons.org/ licenses/by/4.0/.

(C) The Author(s) 2021 